\title{
LA COLECCIÓN DE ENTOMOLOGÍA DEL MUSEO NACIONAL DE CIENCIAS NATURALES (CSIC)
}

\author{
I. Izquierdo (*), C. Martín (*), M. París (*) y C. Santos $(*)$
}

\begin{abstract}
RESUMEN
En el presente trabajo se aporta información sobre el volumen y la composición taxonómica y faunística de la colección de Entomología del Museo Nacional de Ciencias Naturales (MNCN) de Madrid, España. Se ofrece un extracto de su inventario, aportando el número de ejemplares y géneros, número de especímenes tipo y táxones representados por ellos, revisores, consultores, etc. También se comentan diversos aspectos de la utilización de la colección y las vías de acceso a la misma. En un Apéndice se listan algunos catálogos y publicaciones elaboradas sobre material depositado en la colección de Entomología.
\end{abstract}

Palabras clave: Entomología, conservación de colecciones, inventario, disponibilidad.

\section{ABSTRACT \\ The entomological collection of the Spanish Museo Nacional de Ciencias Naturales of Madrid (CSIC)}

The present paper gives information on the volume and taxonomic and faunistic composition of the Entomology Collection of the Museo Nacional de Ciencias Naturales (MNCN) in Madrid, Spain. An abstract of the inventory, including number of specimens and genera, number of type specimens and taxa represented by them, revisors, consultants, etc. is displayed. Different aspects of the facilities for consulting the collection and contact ways are commented. Several catalogues and publications on the housed materials in the Entomology Collection are listed as an Appendix.

Key words: Entomology, conservation of collections, inventory, facilities.

\section{Introducción histórica}

La Colección de Entomología del MNCN se sitúa, por su valor científico, representación geográfica y número de insectos conservados, entre las diez primeras de Europa y como la mejor a nivel nacional; teniendo en cuenta sólo el número de ejemplares, se han contabilizado unos dos millones de insectos más un volumen aproximado a éste que corresponde a material pendiente de incorporación.

El objeto de este trabajo es ofrecer una visión general del material conservado, aportando los datos sobre su composición taxonómica y faunística, que se creen más útiles para conocimiento de los usuarios.
Las colecciones del Museo Nacional de Ciencias Naturales tienen su origen en las de P. F. Dávila, con las cuales Carlos III crea en 1771 el Real Gabinete de Historia Natural. Gracias a la corriente ilustrada que se desarrolla por toda Europa a principios del siglo XIX, la Junta de Protección del Museo ordena en 1828 la primera catalogación científica de sus colecciones, que pone de manifiesto la carencia de ejemplares españoles entre el material y el escaso valor científico del que posee, y apunta la necesidad de su crecimiento.

Hay dos figuras clave en la historia del Museo que comparten esta misma inquietud respecto al incremento del volumen e interés de los fondos:

\footnotetext{
* Museo Nacional de Ciencias Naturales. José Gutiérrez Abascal, 2. 28006 Madrid.
} 
Mariano de la Paz Graells e Ignacio Bolívar. Graells impulsa en 1848 la formación de colecciones de fauna española, nombrando corresponsales y organizando intercambios con otras instituciones análogas, nacionales o extranjeras. Desde su nombramiento oficial como catedrático de Zoología en 1838 y durante los años que fue director del centro (1845-1867), se produce el ingreso de tres valiosas colecciones entomológicas conservadas aún en el Museo: en 1843 la de hemípteros y homópteros de Latreille, que se recibe junto a la de coleópteros de E. Carreño; en 1859 la colección Mieg, que se consideraba la mejor colección de insectos ingresada hasta el momento; y entre 1863 y 1866, las remesas con los ejemplares recolectados en el continente americano por los naturalistas integrantes de la Expedición al Pacífico (1862-1866). Se producen otros muchos ingresos durante esta época, como el material recolectado en Cuba por Poey y la propia colección de Graells. Durante esta época, la mayor parte de las colecciones permanecen embaladas y almacenadas durante años en salas no abiertas al público (Barreiro, 1992).

En 1877 Bolívar entra a formar parte del Museo como ayudante de Zoología, e inicia la organización de las colecciones de insectos, estructurándolas en dos partes: una colección de España y otra general con especies de otros países, sobre todo americanos y europeos. Las colecciones más relevantes por su volumen o valor científico ingresadas desde entonces hasta finales de siglo son las de coleópteros de L. Pérez Arcas e I. Bolívar y la de coleópteros hidrofílidos de L. J. Reiche, la de himenópteros de J. Gogorza, la de hemípteros de C. Chicote, odonatos estudiados por E. Selys Longchamps, e insectos de Canarias de Ch. Alluaud. También ingresa un numeroso material enviado por los corresponsales en Cuba y Filipinas (Dusmet, 1918, 1919, 1944; Barreiro, 1992; Fuentes AMNCN).

La crisis política y económica del país a finales del siglo XIX va sumiendo al Museo en una situación de aislamiento respecto a otros centros, pero con el paso de Bolívar a su dirección en 1901 se consigue recuperar el ritmo establecido por Graells, con nuevos nombramientos de corresponsales, el reinicio de importantes intercambios y adquisiciones, la organización de expediciones científicas a las colonias africanas (Marruecos, Guinea y Sahara) y la solicitud a especialistas españoles y extranjeros para que lleven a cabo el estudio de los fondos almacenados. Las colecciones más relevantes ingresadas desde este momento hasta el comien- zo de nuestra Guerra Civil fueron: las de lepidópteros de A. Fernández, J. Lauffer, J. Riaño, T. Seebold y P.A. Wytsman; dípteros paleárticos de G. Strobl y las de J. Arias Encobet y J. Gil Collado, también de este orden; himenópteros de R. García Mercet; coleópteros de M. Martínez de la Escalera y C. Bolívar; ortópteros de I. Bolívar; colémbolos de F. Bonet; y los insectos recolectados en Marruecos por M. Martínez de la Escalera (Dusmet, 1918, 1919, 1944; Barreiro, 1992; Fuentes AMNCN).

Poco después de la Guerra Civil, en 1941, se crea el Instituto Español de Entomología, formado por el Departamento de Entomología del antiguo Museo, cuya existencia como centro independiente abarca desde este año hasta 1984. Durante este tiempo se mantiene la entrada de ejemplares en sus colecciones gracias a las numerosas aportaciones realizadas por entomólogos y naturalistas españoles. Se pueden destacar en este periodo: la colección de coleópteros de J. Lauffer (que incluía la de F. Martínez Sáez), los coleópteros de Guinea de L. Báguena, los catópidos de R. Zariquiey y los curculiónidos de M. González; los lepidópteros de R. Agenjo, D. Hospital y M. Pujol; los himenópteros de J. M. Dusmet, G. Ceballos y J. J. del Junco y los esfécidos de J. Giner Marí; los ortópteros de Marruecos y Venezuela de E. Morales Agacino; los homópteros de J. Gómez Menor; los insectos de Canarias de A. Cabrera más los recolectados en las expediciones a Guinea Ecuatorial de E. Ortiz y J. Mateu y de S. V. Peris y J. Álvarez.

En 1984 el Instituto, junto a otros dos centros del CSIC, forma el actual Museo Nacional de Ciencias Naturales, en el cual se inicia una etapa de renovación de todos sus departamentos; como parte de la misma se crea por primera vez, en 1990, un Departamento de Colecciones desvinculado de los de investigación, aunque en contacto directo con ellos. Durante los últimos años, continúan las relaciones con museos y entomólogos de todo el mundo y las colecciones de insectos siguen desarrollándose. Entre los ingresos recientes se puede destacar el material reunido por J. Templado, los himenópteros mutílidos y esfécidos de F. J. Suárez, los coleópteros de Mozambique de A. R. Moura, las colecciones particulares de M. A. Alonso Zarazaga (curculiónidos) y A. Cobos (bupréstidos y elatéridos), y la de insectos parásitos del Instituto López Neyra (CSIC). A estos ingresos habría que añadir los numerosos insectos de todos los órdenes recolectados a través de los proyectos de investigación en los que participa el Museo, gracias a los cuales se ingresa no sólo material de la Península Ibérica, sino también de otros países. 


\section{Composición de la colección}

Consideraciones previas. - Antes de pasar a comentar las características de los fondos integrantes de la colección, parece oportuno incluir varias observaciones que aclararán algunos de los aspectos que se comentan posteriormente.

La Colección de Entomología nunca había dispuesto de algún catálogo o inventario completo en el que figuraran registros de sus fondos y que se utilizara como un sistema de acceso al material y fuente de información sobre el mismo. Sólo a partir de 1985 se comenzó a organizar un sistema de documentación (con listados y archivos relacionados) sobre los ejemplares de la colección. Actualmente se encuentra inventariado un $78 \%$ del material conservado en seco, y sus datos están informatizados en un $20 \%$. Este inventario, aún sin completar, nos indica que el MNCN es depositario de una colección de elevado valor histórico y científico; por ejemplo, entre el material registrado hasta 1997 se han localizado 17.016 ejemplares tipo, y un elevado porcentaje de los fondos han sido estudiados y publicados por relevantes especialistas nacionales y extranjeros.

En general, se ha evitado mencionar el número de especies de cada grupo taxonómico representadas en la colección, debido principalmente a que una gran parte del material presenta criterios taxonómicos y nomenclaturales no actualizados, situación que ha ido paulatinamente cambiando. En este sentido, además de las investigaciones realizadas por personal del Museo, se han atendido, sólo en los últimos diez años, 431 visitas de especialistas y 841 solicitudes de préstamos para estudio que han tenido como resultado directo la puesta al día de numeroso material.

Respecto a la organización de la colección, el material se encuentra agrupado taxonómicamente por órdenes, como es tradicional, y en cada uno de ellos existen diversas colecciones según criterios sistemáticos y geográficos. Hay que señalar que hasta la fecha se han mantenido las distintas colecciones faunísticas preexistentes y que por ese motivo no existe un criterio geográfico homogéneo de separación. Habitualmente se presentan al menos tres colecciones según su procedencia: fauna ibérica, material de Canarias y el resto de las áreas agrupadas en una colección general; no obstante, hay algunos órdenes con una única colección de cobertura mundial y otros que presentan varias colecciones de áreas geográficas restringidas (Marruecos, Guinea Ecuatorial, etc.), además de las tres mencionadas.
En relación a los ejemplares tipo, parece importante señalar ante todo que su localización, identificación y registro se produce habitualmente en alguna de las siguientes circunstancias: en el inventario de un determinado material o colección; durante la revisión o estudio de un grupo; por solicitud concreta de una determinada serie tipo; o por haber sido donados. Aunque la mayor parte de los tipos registrados proceden del material inventariado, se sabe que entre el mismo faltan por localizar un elevado número de ellos, ya que es frecuente que no exista en los ejemplares ninguna indicación de su categoría como tipos y porque, durante el proceso de catalogación, no se dispone del tiempo ni de toda la bibliografía que sería necesaria para una labor tan exhaustiva. El número real de tipos será, por lo tanto, considerablemente más elevado.

Estructuración de los datos.- La información que se ofrece sobre la colección de Entomología se ha estructurado en tres diferentes niveles. Se da, en primer lugar, una visión global de la misma mediante un cuadro que refleja el número de especímenes o muestras de cada orden, atendiendo a su forma de preparación. En el segundo nivel de información se aporta la composición y características del material de cada orden en una ficha-resumen, en la que los datos se organizan bajo epígrafes comunes (inventario e informatización, número de ejemplares, ordenación y composición del material, material pendiente de estudio, táxones representados por ejemplares tipo y observaciones). Por último, para aquellos órdenes en que se ha estimado conveniente, se ofrece un tercer nivel en el que se reflejan, en forma de tabla, las cifras y datos de cada grupo taxonómico concreto. Aparte se da la información relativa a los fondos ubicados separadamente de las colecciones taxonómicas pricipales conservadas en seco: material en alcohol, muestras vegetales y colecciones didácticas. La ordenación de los táxones (órdenes, subórdenes, superfamilias y familias) es siempre alfabética.

A continuación se hacen algunas aclaraciones sobre la información incluida en cada epígrafe o apartado de las fichas y tablas.

- Se indica si el material está o no inventariado e informatizado, y la fecha de su realización. Hay que tener en cuenta que los inventarios efectuados son registros de nombres científicos de táxones, es decir, que se incluyen también sinonimias y a veces nombres actualmente no válidos; pueden haberse fichado incluso algunos nombres sin publicar.

- Se ofrece el número de especímenes, preparaciones microscópicas, lotes de material en alcohol y 
muestras vegetales existentes en cada grupo. El material producto de proyectos de investigación desarrollados en el centro, que todavía se encuentra en estudio, no ha sido ingresado aún en la colección y, por lo tanto, no se contabiliza como parte de ella; un resumen del mismo figura en el apartado Material pendiente de incorporación.

- Se describe la organización del material de cada orden y su composición taxonómica y geográfica. Como norma general cada agrupación faunística se consigna con el nombre del área geográfica correspondiente (por ejemplo, Marruecos, Canarias, Paleártica, ...). Hay que tener en cuenta que estas colecciones son excluyentes entre sí, de forma que en los grupos en que se mencionan colecciones de áreas geográficas restringidas no se encontrará material de esas procedencias en ninguna otra colección aunque su ámbito gográfico englobe al de las mencionadas; tampoco se encontrará en la colección que denominamos General. Se reseña el número total de géneros representados en cada orden y, para cada fauna, el porcentaje de identificación, el número de ejemplares, de géneros, y a veces también el de especies.

- Se informa del volumen de material pendiente de estudio, tanto del que se encuentra integrado en las colecciones sistemáticas (mediante un porcentaje de identificación), como del que se agrupa en las misceláneas o almacenes existentes en cada uno de los órdenes.

- Se contabiliza el número de táxones de los que existe material tipo, así como el número total de ejemplares de las series y los autores más destacados de los mismos. En muchos casos se informa también sobre la procedencia geográfica de los tipos. En grupos sin inventariar se indica, en algunas ocasiones, el número de táxones representados por ejemplares tipo localizados hasta el momento.

- También se hace mención de autores y especialistas que han contribuido de una u otra forma al desarrollo de la colección. En cada orden se enumeran, por un lado, aquellos que han destacado a lo largo del tiempo por importantes aportaciones tanto científicas como de material y, por otro, los actuales consultores y revisores de material de la colección; los nombres de los revisores se han incluido en las tablas, en el apartado de observaciones de la familia de insectos correspondiente a su especialidad.

Composición taxonómica y geográfica.- Se ha resumido el contenido de la Colección de Entomología en el siguiente cuadro, en el que se desglosa el número de ejemplares por órdenes y forma de preparación (material en seco montado en alfileres entomológicos, preparaciones microscópicas y lotes de material en alcohol), así como las muestras vegetales. El criterio alfabético en que se presentan los órdenes en este cuadro es el que se sigue, también, para dar la información relativa a cada uno de ellos en este trabajo.

\begin{tabular}{|c|c|c|c|c|}
\hline ORDEN & $\begin{array}{l}\text { MAT. } \\
\text { SECO }\end{array}$ & $\begin{array}{l}\text { PREP. } \\
\text { MICR. }\end{array}$ & ALCOHOL & $\begin{array}{l}\text { MUES. } \\
\text { VEG. }\end{array}$ \\
\hline Anoplura & - & 117 & - & - \\
\hline Blattaria & 6.730 & 99 & 66 & - \\
\hline Coleoptera & 992.246 & 2.800 & 804 & 13 \\
\hline Collembola & - & 16.048 & 2.312 & - \\
\hline Dermaptera & 6.170 & 22 & 52 & - \\
\hline Diplura & - & - & 19 & - \\
\hline Diptera & 54.347 & 2.139 & 694 & 144 \\
\hline Embioptera & 28 & - & 16 & - \\
\hline Ephemeroptera & 290 & - & 9 & - \\
\hline Hemiptera & 45.897 & - & 335 & 3 \\
\hline Homoptera & 16.839 & 2.276 & 368 & 1.410 \\
\hline Hymenoptera & 326.923 & 1.148 & 3.622 & 414 \\
\hline Isoptera & 241 & - & 32 & - \\
\hline Lepidoptera & 330.786 & 9.166 & 424 & 13 \\
\hline Mallophaga & - & 2.782 & - & - \\
\hline Mantodea & 4.523 & 9 & 16 & - \\
\hline Mecoptera & 139 & - & - & - \\
\hline Megaloptera & 92 & - & 1 & - \\
\hline Neuroptera & 4.023 & - & 220 & - \\
\hline Odonata & 7.458 & - & 36 & - \\
\hline Orthoptera & 103.109 & 91 & 385 & - \\
\hline Phasmoptera & 2.366 & - & - & - \\
\hline Plecoptera & 359 & - & 16 & - \\
\hline Protura & - & - & 129 & - \\
\hline Psocoptera & 204 & - & 558 & - \\
\hline Raphidioptera & 83 & - & 12 & - \\
\hline Siphonaptera & - & 549 & 6 & - \\
\hline Strepsiptera & - & - & 13 & - \\
\hline Thysanoptera & 50 & - & 412 & - \\
\hline Thysanura & 64 & - & 295 & - \\
\hline Trichoptera & 1.736 & - & 80 & - \\
\hline Miscelánea & 8.642 & - & 4.401 & 168 \\
\hline TOTAL & 1.913 .345 & 37.246 & 15.333 & 2.165 \\
\hline
\end{tabular}

Entre estos fondos destaca el número de ejemplares tipo ya que, hasta 1997, se han registrado 17.016 especímenes pertenecientes a series tipo de 5.269 táxones descritos de 126 países.

\section{Colecciones taxonómicas}

A continuación se ofrecen las fichas-resumen y las tablas relativas al material de cada uno de los órdenes.

\section{ANOPLURA}

Pendiente de inventario. Existe una única colección de fauna paleártica (fundamentalmente de España y Marruecos) que reúne 117 preparaciones microscópicas. 


\section{BLATTARIA}

Inventario e informatización: El inventario se realizó en 1987, aunque está pendiente el de los ejemplares conservados en alcohol. El material tipo está informatizado.

Número de ejemplares: En la colección se conservan 6.730 ejemplares montados en seco, 99 preparaciones microscópicas y 66 lotes de material conservado en alcohol.

Ordenación y composición del material: El criterio de organización del material es geográfico y está agrupado en las siguientes colecciones: fauna ibérica, Canarias, Marruecos, Ifni-Sahara, Guinea Ecuatorial, fauna paleártica y una colección no paleártica que reúne los ejemplares procedentes de las restantes áreas. Cada una de estas colecciones geográficas está ordenada sistemáticamente.

A continuación se desglosa el número de géneros, ejemplares y el porcentaje de material identificado.

\begin{tabular}{lccc} 
Fauna & $\mathbf{N}^{\mathbf{0}}$ gén. & $\mathbf{N}^{\mathbf{0}}$ ejs & \% ident. \\
\hline Ibérica & 10 & 1.189 & 90 \\
Canarias & 11 & 313 & 100 \\
Paleártica & 26 & 1.398 & 100 \\
No paleártica & 155 & 3.087 & 75
\end{tabular}

El total de géneros representados es de $160 \mathrm{y}$ son 5.987 los ejemplares estudiados.

Material pendiente de estudio: Existen 743 ejemplares sin estudiar, cuya procedencia es fauna ibérica, 43; material de las islas Canarias, 13; región paleártica, 42; y resto de las áreas, 645. Los 66 lotes en alcohol (6 de fauna ibérica y 60 de fauna no paleártica) también están pendientes de estudio.

Táxones representados por ejemplares tipo (localizados hasta 1997): Se han localizado 459 ejemplares tipo, que corresponden a 142 táxones descritos por 15 autores, entre los que destacan: I. Bolívar, que describió 70, H. Bohn, 19, R. Shelford, 16 y M. Hebard, 10. El número de táxones y ejemplares tipo, según su procedencia geográfica, se detalla en la siguiente tabla.

\begin{tabular}{lcc} 
Fauna & Táxones & $\mathbf{N}^{\mathbf{0}}$ ejs \\
\hline Ibérica & 32 & 63 \\
Canarias & 3 & 6 \\
Paleártica & 28 & 270 \\
No paleártica & 79 & 120
\end{tabular}

Observaciones: Esta colección contiene importantes aportaciones científicas y de material de $\mathrm{N}$. Adelung, J. Almeida Fernández, C. Bolívar Pieltáin, I. Bolívar, M. Cazurro, K. Harz, E.
Morales Agacino, J. Olcese, R. Shelford. La colección ha sido consultada en los últimos años por E. Gutiérrez.

\section{COLEOPTERA}

Inventario e informatización: Actualmente se ha inventariado alrededor de un $73 \%$ de los fondos conservados en seco. De las 166 familias de coleópteros en que actualmente se considera dividido este orden, 110 están representadas en la colección. El material de 54 de ellas está inventariado y el inventario de 17 de éstas se ha informatizado. También está informatizado el material tipo de los grupos inventariados, los tipos localizados en familias no inventariadas y los que ingresan a la colección debido a donaciones. Los coleópteros conservados en fluido están, en un elevado porcentaje, pendientes de inventario.

Número de ejemplares: El inventario recoge 698.683 ejemplares de coleópteros que, junto a los casi 280.000 especímenes que se estima faltan por inventariar, hacen un total de unos 978.683 ejemplares conservados en seco. Existen también 804 lotes de ejemplares conservados en fluido y 2.800 preparaciones microscópicas.

Ordenación y composición del material: Generalmente la ordenación es sistemática, existiendo para cada una de las familias colecciones separadas según la fauna. Las subcolecciones más usuales son: material de fauna ibérica, islas Canarias, Marruecos, Guinea Ecuatorial y colección General con representación del resto de las áreas geográficas. En el siguiente cuadro, sólo referido al material inventariado, se lista el número de géneros y de ejemplares según su procedencia.

\begin{tabular}{lcr} 
Fauna & $\mathbf{N}^{\mathbf{0}}$ géneros & \multicolumn{1}{c}{$\mathbf{N}^{\mathbf{0}}$ ejs } \\
\hline Ibérica & 950 & 333.217 \\
Canarias & 298 & 34.301 \\
Marruecos & 733 & 126.461 \\
Guinea Ec. & 243 & 20.272 \\
General & 2.190 & 166.319 \\
Mundial * & 284 & 18.113
\end{tabular}

* Los datos corresponden a familias pequeñas, cuyos ejemplares no se separan por criterios geográficos.

El número total de géneros recogidos en el inventario es 3.861. Existe una interesante colección de fauna cavernícola, organizada por $\mathrm{C}$. Bolívar Pieltáin, que reúne 7.763 ejemplares. Del material en alcohol están estudiados 8.579 ejemplares de la familia Scarabaeidae. En la Tabla 1 se ofrecen algunos datos sobre la composición taxo- 


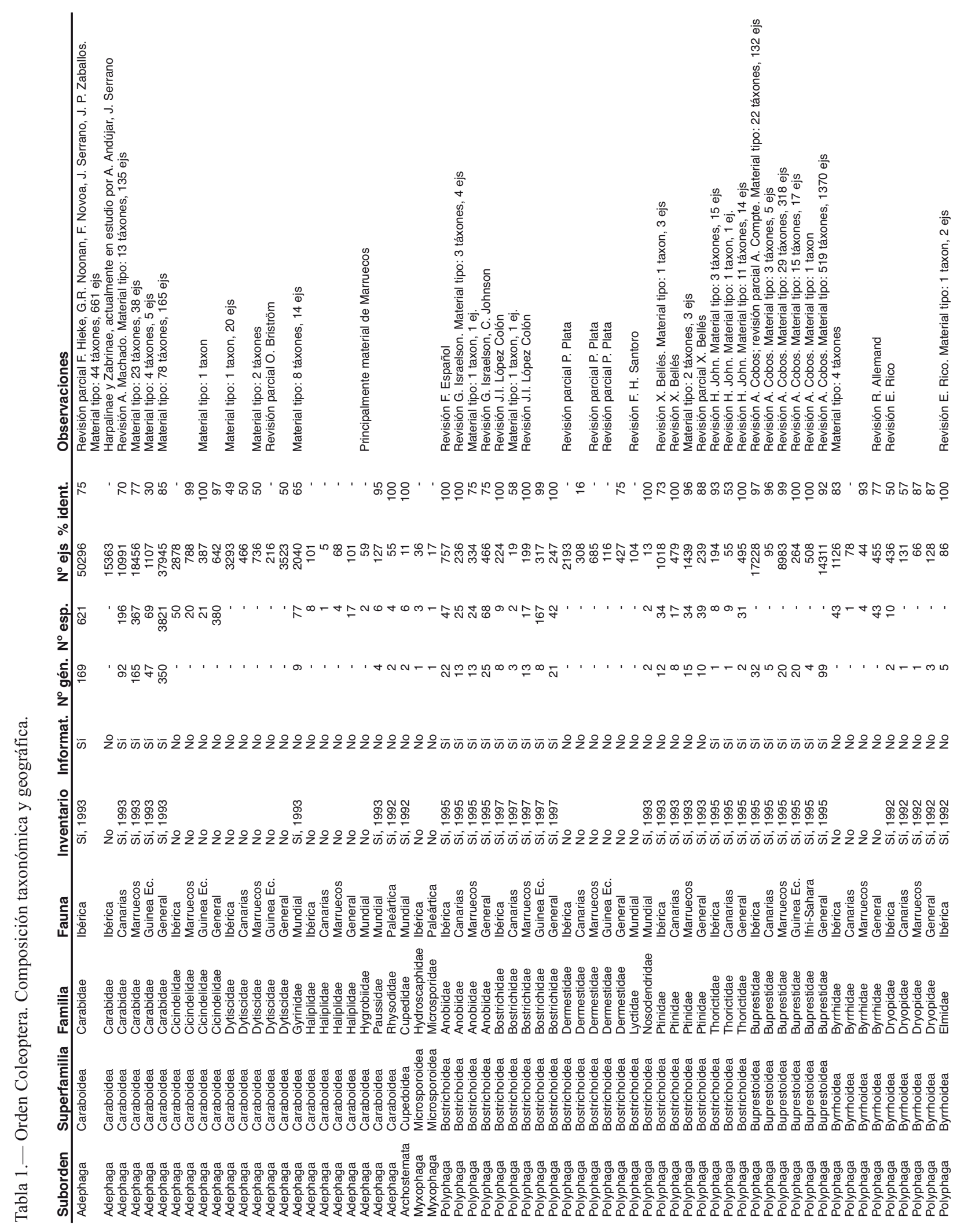



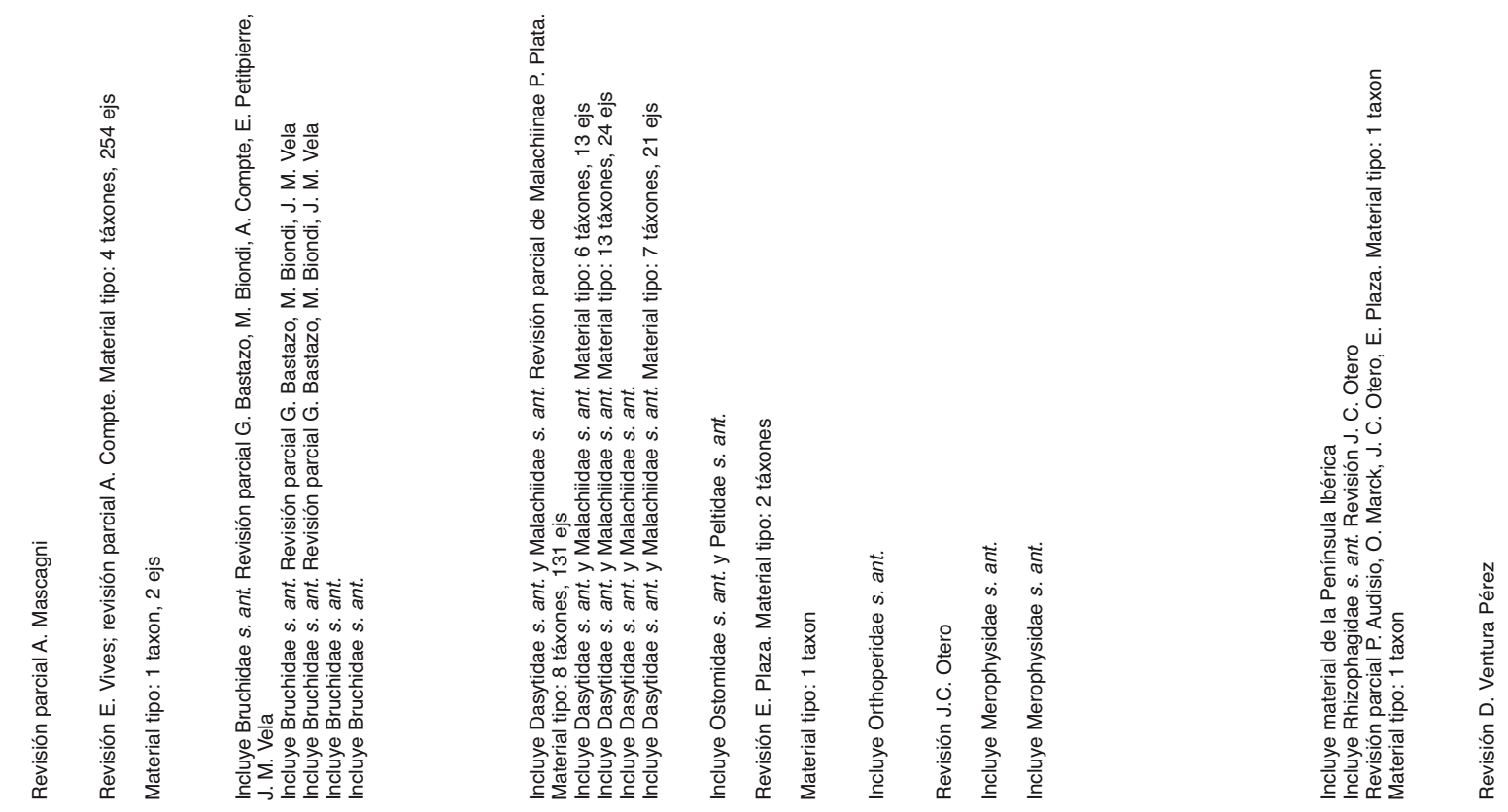

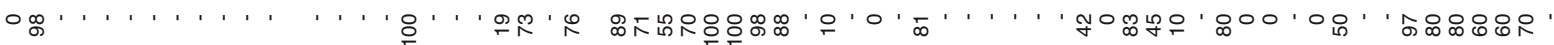

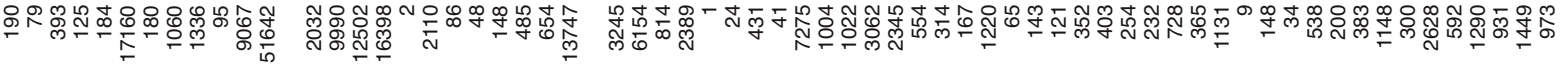

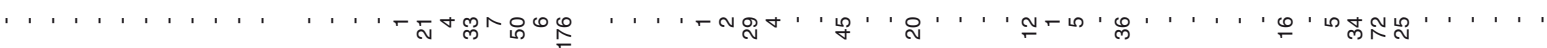

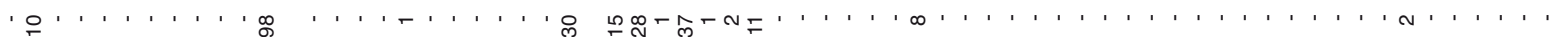

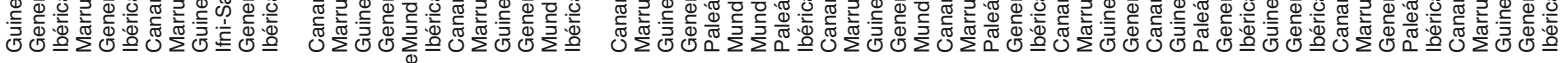

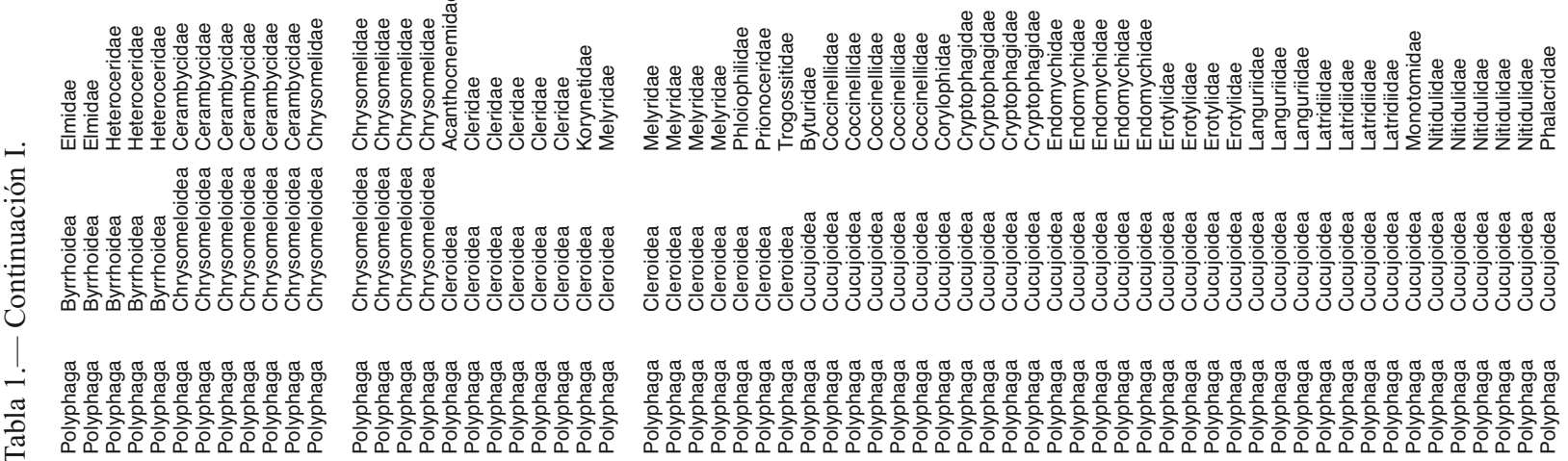




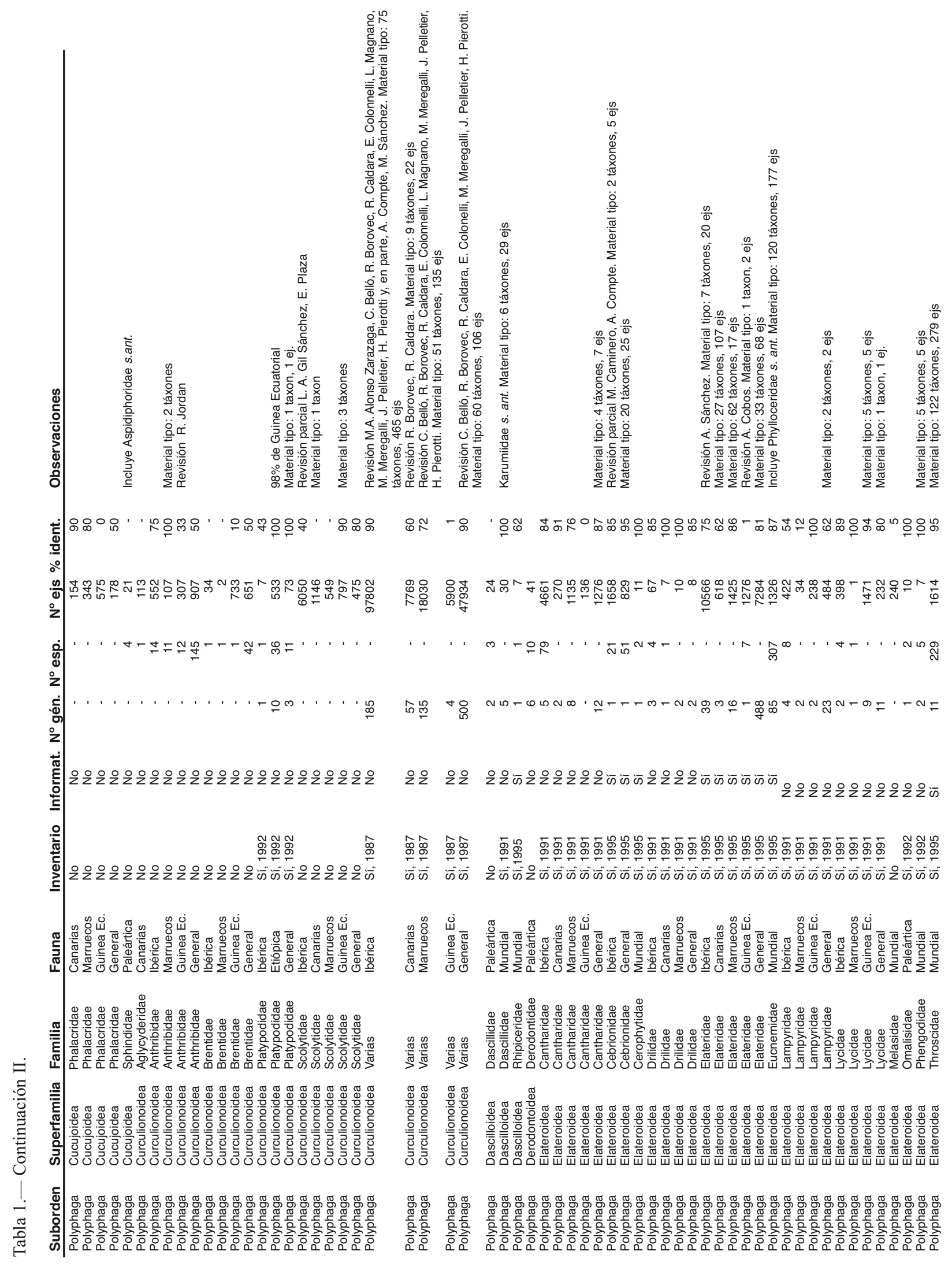




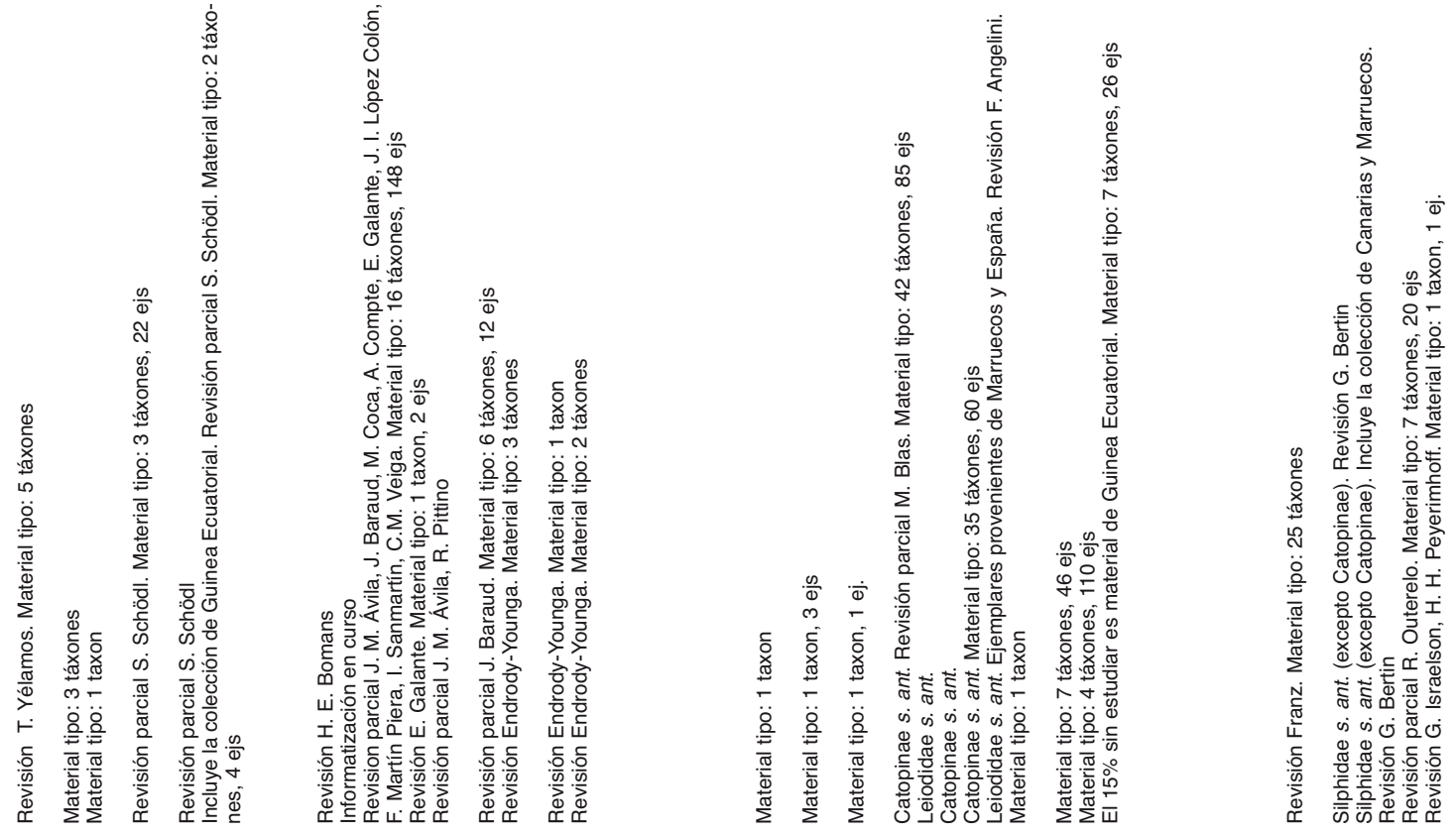

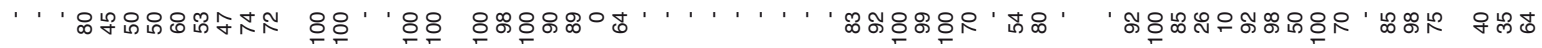

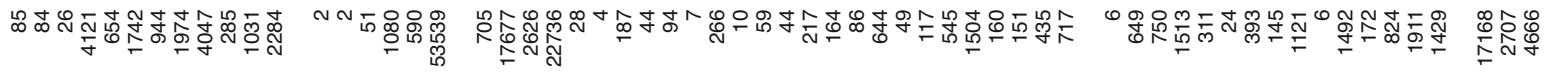

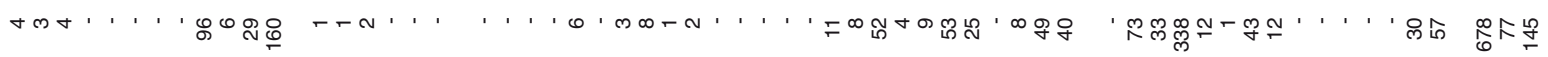
' ' . ' ' ' '

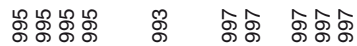

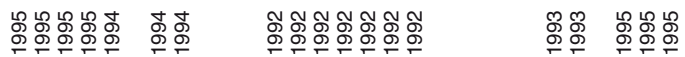

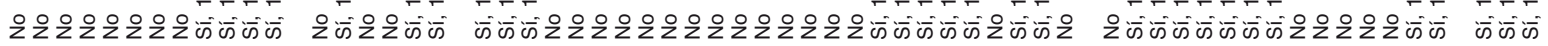

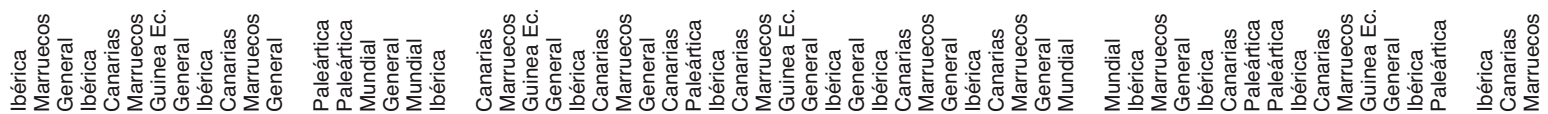

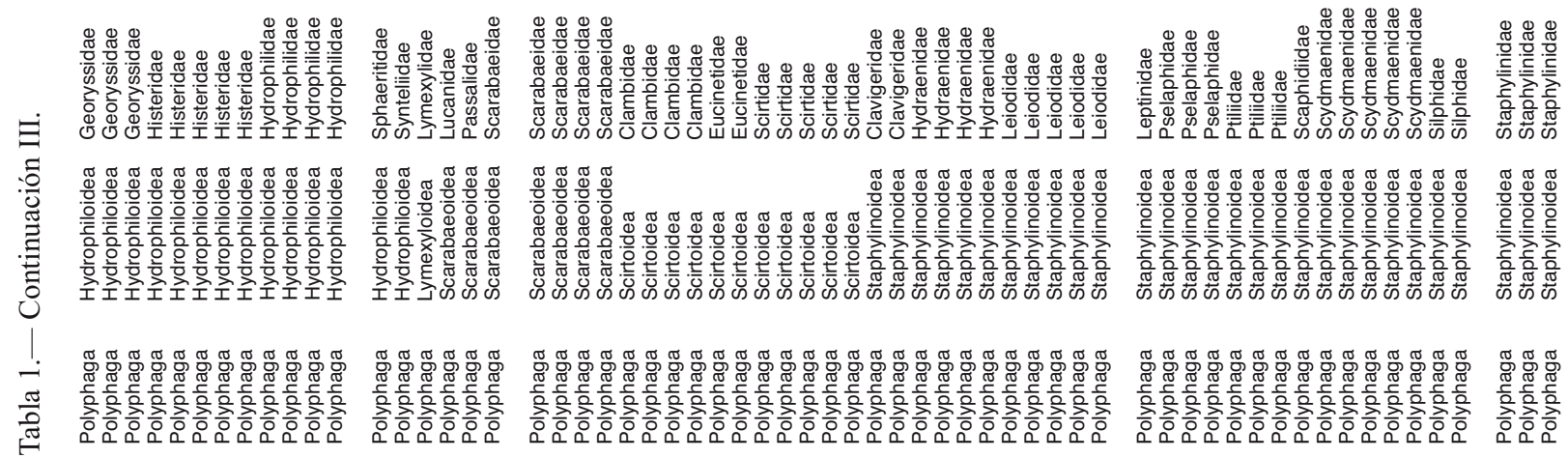




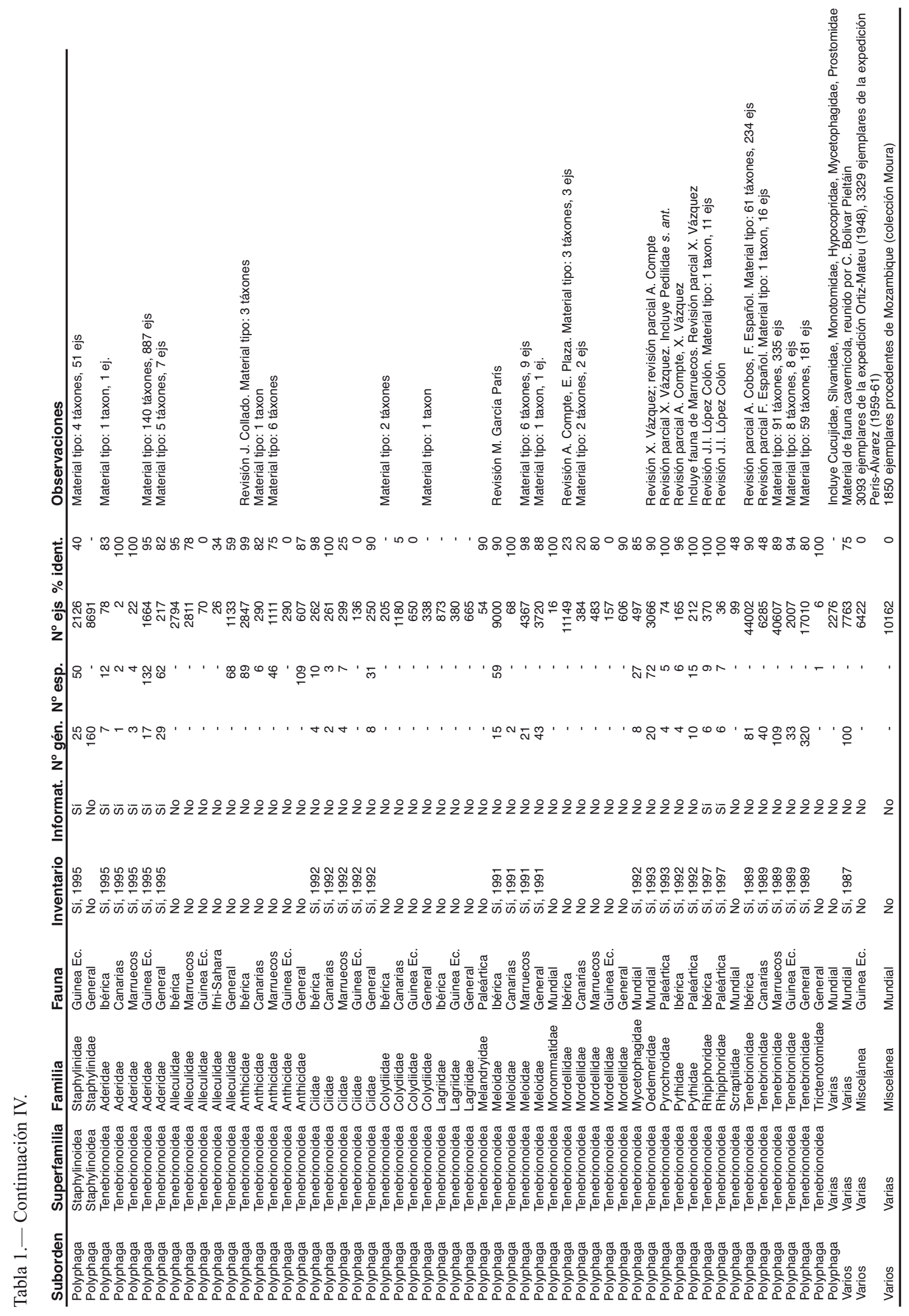


nómica y faunística del material de este orden; el criterio seguido para la agrupación de superfamilias y familias es, básicamente, el de Lawrence \& Newton (1995).

Material pendiente de estudio: Hay 16.584 ejemplares en seco pendientes de estudio. Respecto al material en fluido, se conservan sin estudiar 693 lotes de fauna ibérica (incluyendo 17 lotes de larvas), 3 de fauna canaria y 2 de otras áreas de la región paleártica.

Táxones representados por ejemplares tipo (localizados hasta 1997): Hasta ahora se han localizado 7.144 ejemplares tipo de 1.989 táxones descritos por 170 autores, entre los cuales destacan A. Cobos (492), M. Martínez de la Escalera (239), L. Báguena (86), J. Obenberger (41), R. Jeannel (31), C. Bolívar Pieltáin (30), J. Desbrochers (25), F. Español (24), M. Antoine (23), L. Fairmaire (23) y M. A. Alonso Zarazaga (21). El material tipo se desglosa, por faunas, en el cuadro siguiente.

\begin{tabular}{lcr} 
Fauna & Táxones & $\mathbf{N}^{\mathbf{0}} \mathbf{e j}$ \\
\hline Ibérica & 312 & 2.291 \\
Canarias & 69 & 312 \\
Marruecos & 255 & 1.029 \\
Guinea Ec. & 184 & 990 \\
General & 1.078 & 2.522
\end{tabular}

Observaciones: Se pueden destacar las aportaciones científicas y de material de E. Abeille de Perrin, L. Báguena, L. Bedel, C. Besuchet, C. Bolívar Pieltáin, J. Bourgeois, S. Breunning, E. C. A. Candèze, E. Carreño, A. Cobos, H. D’Orbigny, F. Español, A. Evers, L. Fairmire, A. Fauvel, M. García de Viedma, H. Gebien, M. González, M.P. Graells, E. Gridelli, F. Hauser, W. Horn, R. Jeannel, H. Jekel, C. Kerremans, C. Koch, H. KrekichStrassoldo, A. A. L. Lameer, J. Lauffer, P. Lesne, G. Lewis, F. Martínez de la Escalera, M. Martínez de la Escalera, F. P. Martínez Sáez, J. Mateu, A. R. Moura, E. Moroder, J. Obenberger, A. Pardo Alcaide, L. Pérez Arcas, K. Petri, H. H. Peyerimhoff, M. Pic, N. N. Plavilstschikov, S. Prado Sainz, E. Reitter, F. G. Rambousek, Schedl, J. Schramm, S. Uhagón, J. Weise, E. Zarco, R. Zariquiey.

La colección ha sido consultada en los últimos años por D. Ahrens, I. Alonso, L. Arnaiz, P. A. Audisio, P. Bahillo de la Puebla, J. Balciunas, E. Barbero, L. Bartolozzi, C. L. Bellamy, P. Bercedo, P. Berger, J. P. Besson, O. Biström, M. A. Bologna, D. Briese, F. M. Buzzetti, R. Caldara, C. Camacho, E. Carabajal, A. Casale, J. Collado, J. M. Crespo, G. Curletti, G. Coulon, M. Daccordi, J. A. Delgado,
A. C. Deloya, L. Diodato, A. Dostal, S. Eizaguirre, J. A. Fernández Cortés, A. Fernández Sanz, M. C. Ferreira, M. J. Gámez de la Torre, R. García Becerra, J. García Carrillo, M. Gianluca, M. Gil Pinilla, C. Girard, M. A. Godoy, L. González, C. F. González Peña, I. Gonzalo Fidel, P. Gurrea, T. Heijerman, J. J. Hernández Pacheco, J. M. Hernández de Miguel, C. Hernando, J. Horák, C. Huber, F. Huerta, A. Konstantinov, M. Kost'ál, R. Krause, H. Labrique, D. W. Langor, J. L. Lencina, F. Llobera, M. J. Lombardero, D. Makhan, J. M. Marcos, C. Martín Cantarino, A. V. Matalín, E. Micó, A. Moczek, F. Molino, O. Montreuill, G. R. Noonan, E. Núñez Pérez, T. Nyholm, C. Olmos, V. Ortuño, J. A. Pajares, M. Palmer, R. Peña Léon, J. J. Pino Pérez, J. Plaza, A. Quirós, R. Rebolledo, J. A. Regil, J. A. Revenga, I. Ribera, E. Rico, F. Rodríguez Fernández, S. Roig, J. Romero Samper, E. Ron, J. L. Ruiz García, I. Ruiz Tapiador, J. Ruzicka, J. A. Sáez Bolaño, F. Sánchez Piñero, M. A. Sánchez Sobrino, J. M. Santamaría, S. Santamaría, M. J. Sanz Benito, A. del Saz, J. Scheuern, K. Schön, J. Sieg, A. Simón Sorlí, P. Téocchi, R. T. Thompson, M. Tomé, M. Toribio, P. de Uries, L. F. Valladares, X. A. Vázquez, A. Velázquez de Castro, D. Ventura, A. Verdugo Páez, P. Veronese, A. Warchalowskii, P. Wegrzynowicz, C. Wurst, J. L. Zapata, M. Zunino.

\section{COLLEMBOLA}

Inventario e informatización: El inventario del material conservado en preparaciones microscópicas fue realizado en 1993 por J. C. Simón Benito. Los datos se informatizaron en 1994. No existe, por el momento, un inventario completo del material conservado en alcohol.

Número de ejemplares: Se conservan 16.048 preparaciones microscópicas y 2.312 lotes preservados en fluido.

Ordenación y composición del material: El material está organizado en dos colecciones: una de fauna paleártica, fundamentalmente ibérica $(95 \%$ identificado a nivel de especie) y otra más reducida de cobertura mundial (70\% identificado a nivel de especie). En el siguiente cuadro se resume el número de géneros, especies y preparaciones de ambas colecciones.

\begin{tabular}{lrrrrrr} 
& \multicolumn{3}{c}{$\begin{array}{c}\text { Col. General } \\
\text { (Paleártica) }\end{array}$} & \multicolumn{3}{c}{$\begin{array}{c}\text { Col. Bonet } \\
\text { (Mundial) }\end{array}$} \\
\cline { 2 - 7 } Superfamilia & \multicolumn{1}{c}{$\mathbf{N}^{\circ}$ gén. } & spp. & $\mathbf{N}^{\mathbf{0}}$ prep. & \multicolumn{2}{c}{$\mathbf{N}^{\mathbf{0}}$ gén. } & spp. $\mathbf{N}^{\mathbf{0}}$ prep. \\
\hline Neelipleona & 2 & 3 & 153 & 2 & - & 6 \\
Poduromorpha & 80 & 385 & 13.068 & 51 & 123 & 1.525 \\
Symphypleona & 23 & 53 & 983 & 9 & 21 & 110 \\
Varias & - & - & - & 3 & - & 14
\end{tabular}


En conjunto están representados 114 géneros. En la Tabla 2 se desglosa la composición taxonómica de ambas colecciones; los criterios de clasificación adoptados en la tabla son los de Jordana et al. 1990 y 1997.

Respecto al material conservado en alcohol, están estudiados 523 lotes: 500 provienen de la Península Ibérica y 23 de otras áreas geográficas.

Material pendiente de estudio: Restan por estudiar 193 preparaciones microscópicas y 1.789 lotes en alcohol; de éstos, 1.650 son de fauna ibérica y 139 de otras áreas.

Táxones representados por ejemplares tipo (localizados hasta 1997): Se conserva material tipo de 86 táxones descritos por 12 autores, entre ellos M. Acón, J. I. Arbea, F. Bonet, R. Jordana, D. Selga, J. C. Simón y W. Steiner.

Observaciones: La colección ibérica fue formada a partir de los años sesenta por D. Selga y el equipo de Fauna del Suelo de los antiguos Institutos de Edafología y Español de Entomología (CSIC). La de cobertura mundial la constituye el material reunido por F. Bonet hasta 1936.

Tabla 2.- Orden Collembola. Composición taxonómica y geográfica.

\begin{tabular}{|c|c|c|c|c|c|}
\hline Superfamilia & Familia & Fauna & $\mathrm{N}^{\circ}$ gén. & $\mathrm{N}^{\circ}$ esp. & $\mathrm{N}^{\circ}$ prep. \\
\hline Neelipleona & Neelidae & Paleártica & 2 & 3 & 153 \\
\hline Neelipleona & Neelidae & Mundial & 2 & - & 6 \\
\hline Poduromorpha & Actaletidae & Mundial & 1 & 1 & 1 \\
\hline Poduromorpha & Cyphoderidae & Paleártica & 1 & 5 & 21 \\
\hline Poduromorpha & Cyphoderidae & Mundial & 1 & 3 & 19 \\
\hline Poduromorpha & Entomobryidae & Paleártica & 7 & 53 & 2693 \\
\hline Poduromorpha & Entomobryidae & Mundial & 11 & 21 & 703 \\
\hline Poduromorpha & Hypogastruridae & Paleártica & 12 & 67 & 2280 \\
\hline Poduromorpha & Hypogastruridae & Mundial & 6 & 14 & 218 \\
\hline Poduromorpha & Isotomidae & Paleártica & 20 & 126 & 4345 \\
\hline Poduromorpha & Isotomidae & Mundial & 10 & 46 & 153 \\
\hline Poduromorpha & Neanuridae & Paleártica & 18 & 65 & 1536 \\
\hline Poduromorpha & Neanuridae & Mundial & 11 & 4 & 73 \\
\hline Poduromorpha & Odontellidae & Paleártica & 6 & 10 & 103 \\
\hline Poduromorpha & Oncopoduridae & Paleártica & 1 & 1 & 6 \\
\hline Poduromorpha & Oncopoduridae & Mundial & 1 & 1 & 25 \\
\hline Poduromorpha & Onychiuridae & Paleártica & 12 & 52 & 2020 \\
\hline Poduromorpha & Onychiuridae & Mundial & 6 & 20 & 192 \\
\hline Poduromorpha & Paronellidae & Mundial & 1 & 1 & 1 \\
\hline Poduromorpha & Poduridae & Paleártica & 1 & 1 & 1 \\
\hline Poduromorpha & Poduridae & Mundial & 1 & 1 & 5 \\
\hline Poduromorpha & Tomoceridae & Paleártica & 2 & 5 & 63 \\
\hline Poduromorpha & Tomoceridae & Mundial & 2 & 11 & 135 \\
\hline Symphypleona & Arrhopalitidae & Paleártica & 1 & 9 & 157 \\
\hline Symphypleona & Arrhopalitidae & Mundial & 1 & 5 & 59 \\
\hline Symphypleona & Bourletiellidae & Paleártica & 6 & 11 & 153 \\
\hline Symphypleona & Bourletiellidae & Mundial & 1 & 3 & 11 \\
\hline Symphypleona & Dicyrtomidae & Paleártica & 3 & 5 & 23 \\
\hline Symphypleona & Dicyrtomidae & Mundial & 2 & 4 & 17 \\
\hline Symphypleona & Katiannidae & Paleártica & 2 & 9 & 207 \\
\hline Symphypleona & Katiannidae & Mundial & 2 & 4 & 8 \\
\hline Symphypleona & Sminthuridae & Paleártica & 7 & 11 & 175 \\
\hline Symphypleona & Sminthuridae & Mundial & 2 & 4 & 14 \\
\hline Symphypleona & Sminthurididae & Paleártica & 4 & 8 & 268 \\
\hline Symphopleona & Sminthurididae & Mundial & 1 & 1 & 1 \\
\hline Varias & Varias & Mundial & 3 & - & 14 \\
\hline Varias & Miscelánea & Paleártica & - & - & 4 \\
\hline Varias & Miscelánea & Mundial & - & - & 189 \\
\hline
\end{tabular}

El material de la colección ha sido revisado por M. Acón, J. Arbea, R. Jordana, M. J. Luciáñez y J. C. Simón; también ha sido consultada en los últimos años por M. J. Brelfeld, A. Fjellberg, E. Mateos, J. Najt, J. M. Thibaud

\section{DERMAPTERA}

Inventario e informatización: $\mathrm{El}$ inventario del material conservado en seco se realizó en 1987; está pendiente el del material en fluido. Los táxones con material tipo están informatizados.

Número de ejemplares: Se han contabilizado 6.123 ejemplares montados en seco y 52 lotes con especímenes conservados en alcohol. Hay también 22 preparaciones microscópicas de distintas estructuras anatómicas de los ejemplares.

Ordenación y composición del material: El criterio de organización del material es geográfico y está agrupado en las siguientes colecciones: fauna ibérica, Canarias, Marruecos, Ifni-Sahara, Guinea Ecuatorial, fauna paleártica y una colección no paleártica que reúne los ejemplares procedentes de las restantes áreas. Cada una de estas colecciones geográficas está ordenada sistemáticamente. El número de géneros y ejemplares del material ya estudiado aparece en el siguiente cuadro.

\begin{tabular}{lcc} 
Fauna & $\mathbf{N}^{\mathbf{0}}$ gén. & $\mathbf{N}^{\mathbf{0}}$ ejs \\
\hline Ibérica & 15 & 2.516 \\
Canarias & 8 & 1.213 \\
Paleártica & 13 & 806 \\
No paleártica & 44 & 1.146
\end{tabular}

El número total de géneros representados en esta colección es de 66. En la Tabla 3 se ofrecen algunos datos sobre la composición taxonómica y faunística del material.

Material pendiente de estudio: Existe un almacén de 442 ejemplares (7\% del total) sin estudiar; de éstos, 152 son ejemplares de fauna ibérica y 290 de fauna no paleártica. Todo el material en alcohol está sin estudiar: 24 lotes de fauna ibérica, 7 de Canarias y 21 lotes de otras faunas.

Táxones representados por ejemplares tipo (localizados hasta 1997): Se han localizado 48 ejemplares tipo de 20 táxones descritos por 6 autores. Los que han descrito la mayor parte de estos táxones son A. Bormans (8 táxones), M. Burr (4) e I. Bolívar (3). El material tipo se desglosa por faunas en el siguiente cuadro.

\begin{tabular}{lcc} 
Fauna & Táxones & $\mathbf{N}^{\mathbf{0}}$ ejs \\
\hline Canarias & 1 & 3 \\
Marruecos & 1 & 2 \\
Otras faunas & 18 & 43
\end{tabular}


Tabla 3.- Orden Dermaptera. Composición taxonómica y geográfica.

\begin{tabular}{lllrrr} 
Superfamilia & Familia & Fauna & $\mathbf{N}^{\circ}$ gén. & $\mathbf{N}^{\circ}$ ejs & \%ident. \\
\hline Forficuloidea & Chelisochidae & Ibérica & 4 & 17 & 100 \\
Forficuloidea & Forficulidae & Ibérica & 6 & 2148 & 100 \\
Forficuloidea & Forficulidae & No paleártica & 23 & 571 & 90 \\
Forficuloidea & Labiidae & Ibérica & 1 & 40 & 100 \\
Forficuloidea & Labiidae & No paleártica & 11 & 131 & 100 \\
Forficuloidea & Pygidicranidae & No paleártica & 8 & 109 & 100 \\
Labiduroidea & Carciniphoridae & Ibérica & 2 & 173 & 100 \\
Labiduroidea & Labiduridae & Ibérica & 2 & 138 & 100 \\
Labiduroidea & Labiduridae & No paleártica & 2 & 54 & 75 \\
Varias & Varias & Canarias & 8 & 1213 & 100 \\
Varias & Varias & Paleártica & 13 & 806 & 95 \\
Varias & Miscelánea & Ibérica & - & 152 & 0 \\
Varias & Miscelánea & No paleártica & - & 571 & 0 \\
\hline
\end{tabular}

Observaciones: Esta colección contiene un importante material colectado y/o estudiado por I. Bolívar, M. Burr y E. Morales Agacino. El material paleártico de la colección ha sido revisado por $\mathrm{K}$. Harz. La colección también ha sido consultada en los últimos años por M. Arechavaleta.

\section{DIPLURA}

El material del grupo está pendiente de inventario. Existen 19 lotes conservados en alcohol, $14 \mathrm{de}$ los cuales son de material ibérico.

\section{DIPTERA}

Inventario e informatización: El inventario del material en seco se realizó en 1986 y está pendiente el inventario de los ejemplares conservados en fluido. Está informatizado el material tipo.

Número de ejemplares: La colección cuenta con 52.273 ejemplares montados en seco, 2.139 preparaciones microscópicas y 694 lotes de material conservado en alcohol.

Ordenación y composición del material: El material en seco está organizado en una única colección taxonómica, constituida fundamentalmente por ejemplares de fauna paleártica (alrededor del $80 \mathrm{u}$ $85 \%$ son especímenes de fauna ibérica). La colección incluye representantes de 3.202 especies pertenecientes a 848 géneros. En la Tabla 4 se desglosan estas cifras según el grupo taxonómico al que pertenecen.

Hay 170 lotes de material conservado en fluido que están estudiados: 72 de fauna ibérica y 98 con ejemplares de otras faunas. Existe una colección de preparaciones microscópicas de alas, realizada por F. Jiménez en 1990, que incluye material de 352 especies de varias familias. Se conserva, además, una colección de agallas producidas por dípteros, cuya información se detalla en el apartado Muestras vegetales.

Material pendiente de estudio: Están sin estudiar 17.597 ejemplares montados en seco. Del material preservado en fluido restan por estudiar 518 lotes: 462 de fauna ibérica (incluye 47 lotes con larvas), 4 de Canarias, 4 de Marruecos y 48 (incluye 9 lotes con larvas) de otras áreas.

Táxones representados por ejemplares tipo (localizados hasta 1997): Se han registrado 181 ejemplares tipo de 62 táxones descritos por 17 autores, entre los que destacan J. Gil Collado (23 táxones), Mannheims (6), J. Arias Encobet (5) y G. Strobl (5). El material tipo se desglosa por faunas en el siguiente cuadro.

\begin{tabular}{lcr} 
Fauna & Táxones & $\mathbf{N}^{\mathbf{0}}$ ejs \\
\hline Ibérica & 31 & 109 \\
Canarias & 1 & 2 \\
Marruecos & 14 & 48 \\
Guinea Ec. & 3 & 5 \\
General & 13 & 17
\end{tabular}

Observaciones: Esta colección fue organizada por S.V. Peris y destacan las aportaciones tanto científicas como de material de J. M. Andreu, J. Arias Encobet, J. Gil Collado, L. Nájera Angulo, G. Strobl, J. B. Surcouf.

Esta colección ha sido consultada en los últimos años por M. Báez, F. Collantes, N. L. Evenhuis, L. Greve Jensen, Ho-Yeon Han, F. Jiménez, N. Krivosheina, I. A. W. Lucas, A. I. Martínez Sánchez, M. Muñiz Daza, M. C. Pérez Bañón, M. Portillo, F. Salom, M. D. Soler, E. Sierra, A. Vujic.

\section{EMBIOPTERA}

Inventario e informatización: El material en seco de este orden se inventarió en 1997; está pendiente el conservado en fluido. El inventario no está informatizado.

Número de ejemplares: Se conservan 28 ejemplares montados en seco y 16 lotes en alcohol.

Ordenación y composición del material: Los especímenes están organizados en una única colección. Todo el material es ibérico excepto 1 ejemplar de las islas Canarias.

Material pendiente de estudio: El 100\% de esta colección.

Táxones representados por ejemplares tipo (localizados hasta 1997): No hay material tipo registrado hasta la fecha. 
Tabla 4.- Orden Diptera. Composición taxonómica y geográfica.

\begin{tabular}{|c|c|c|c|c|c|c|}
\hline Suborden & Familia & $\mathrm{N}^{\circ}$ gé & $\mathrm{N}^{\circ}$ es & $\mathrm{N}^{\circ}$ ejs & \%ident. & Observaciones \\
\hline Brachicera & Acroceridae & 10 & 27 & 183 & 100 & Material tipo: 4 táxones, 4 ejs \\
\hline Brachicera & Agromyzidae & 12 & 60 & 198 & 100 & \\
\hline Brachicera & Anthomyzidae & 1 & 2 & 5 & 100 & \\
\hline Brachicera & Asilidae & 57 & 198 & 3864 & 40 & $\begin{array}{l}\text { Incluye material neártico, neotrópical y afrotropical. Material tipo: } 2 \text { táxo- } \\
\text { nes, } 3 \text { ejs }\end{array}$ \\
\hline Brachicera & Astiidae & 1 & 2 & 7 & 100 & \\
\hline Brachicera & Bombyliidae & 29 & 205 & 1843 & - & Incluye material neotropical. Revisión A. Sánchez Terrón \\
\hline Brachicera & Braulidae & 1 & 1 & 6 & 100 & \\
\hline Brachicera & Calliphoridae & 11 & 34 & 997 & 100 & Revisión M. D. González, S. V. Peris \\
\hline Brachicera & Camillidae & 1 & 2 & 11 & 100 & \\
\hline Brachicera & Canaceidae & 2 & 3 & 15 & 100 & \\
\hline Brachicera & Chiromyiidae & 2 & 3 & 4 & 100 & \\
\hline Brachicera & Chloropidae & 28 & 77 & 388 & 100 & \\
\hline Brachicera & Clusiidae & 2 & 3 & 4 & 100 & \\
\hline Brachicera & Clythiidae & 3 & 4 & 7 & 100 & \\
\hline Brachicera & Coelopidae & 2 & 5 & 19 & 95 & \\
\hline Brachicera & Conopidae & 8 & 43 & 535 & 70 & \\
\hline Brachicera & Cypselidae & 2 & 38 & 183 & 100 & \\
\hline Brachicera & Diastatidae & 1 & 3 & 6 & 100 & \\
\hline Brachicera & Dolichopodidae & 49 & 251 & 1624 & 55 & Material tipo: 2 táxones, 2 ejs \\
\hline Brachicera & Dorylaidae & 3 & 12 & 71 & 70 & \\
\hline Brachicera & Driomyzidae & 3 & 5 & 24 & 95 & \\
\hline Brachicera & Drosophilidae & 7 & 23 & 107 & 100 & \\
\hline Brachicera & Empididae & 40 & 245 & 1628 & 60 & \\
\hline Brachicera & Ephydridae & 32 & 107 & 426 & 100 & Revisión M. Krivosheina. Material tipo: 6 táxones, 11 ejs \\
\hline Brachicera & Gasterophilidae & 1 & 6 & 27 & 100 & \\
\hline Brachicera & Helomyzidae & 10 & 31 & 121 & 100 & \\
\hline Brachicera & Larvaevoridae & 86 & 184 & 1039 & 95 & Material tipo: 1 taxon, 1 ej. \\
\hline Brachicera & Lauxanidae & 14 & 44 & 178 & 100 & \\
\hline Brachicera & Lonchaeidae & 2 & 21 & 66 & 100 & \\
\hline Brachicera & Lonchopteridae & 2 & 4 & 376 & 16 & \\
\hline Brachicera & Milichiidae & 5 & 7 & 21 & 95 & \\
\hline Brachicera & Muscidae & 45 & 132 & 2373 & 85 & Revisión S. V. Peris \\
\hline Brachicera & Mydaidae & 5 & 11 & 37 & 100 & Material tipo: 4 táxones, 9 ejs \\
\hline Brachicera & Nemestrinidae & 8 & 28 & 285 & 65 & Material tipo: 4 táxones, 10 ejs \\
\hline Brachicera & Nycteribiidae & 3 & 5 & 26 & 100 & \\
\hline Brachicera & Omphralidae & 1 & 3 & 25 & 100 & \\
\hline Brachicera & Opomyzidae & 2 & 6 & 33 & 100 & \\
\hline Brachicera & Ortalidae & 13 & 31 & 164 & 100 & \\
\hline Brachicera & Phoridae & 10 & 65 & 602 & 60 & Material tipo: 4 táxones, 20 ejs \\
\hline Brachicera & Piophilidae & 1 & 5 & 36 & 30 & \\
\hline Brachicera & Platystomidae & 2 & 7 & 82 & 100 & \\
\hline Brachicera & Psilidae & 10 & 19 & 80 & 100 & \\
\hline Brachicera & Pterocallidae & 1 & 1 & 1 & 100 & \\
\hline Brachicera & Rhagionidae & 8 & 39 & 255 & 60 & \\
\hline Brachicera & Rhinophoridae & 9 & 10 & 57 & 100 & Material tipo: 1 taxon, 5 ejs \\
\hline Brachicera & Sarcophagidae & 19 & 44 & 154 & 100 & Material tipo: 1 taxon, 1 ej. \\
\hline Brachicera & Sciomyzidae & 24 & 55 & 652 & 100 & \\
\hline Brachicera & Sepsidae & 6 & 26 & 623 & 95 & Revisión A. L. Ozerov \\
\hline Brachicera & Stratiomyiidae & 20 & 87 & 637 & 90 & Incluye material de Guinea Ecuatorial \\
\hline Brachicera & Syrphidae & 60 & 282 & 5891 & 60 & Revisión parcial W. Hurkmans, M.A. Marcos. Material tipo: 17 táxones, 57 ejs \\
\hline Brachicera & Tabanidae & 10 & 155 & 2896 & 90 & Revisión M. Portillo. Material tipo: 3 táxones, 13 ejs \\
\hline Brachicera & Tephritidae & 37 & 95 & 1750 & 100 & \\
\hline Brachicera & Tethinidae & 1 & 1 & 2 & 100 & \\
\hline Brachicera & Therevidae & 6 & 18 & 249 & 25 & \\
\hline Brachicera & Trichoscelidae & 1 & 3 & 6 & 100 & \\
\hline Brachicera & Tylidae & 2 & 10 & 66 & 100 & \\
\hline Brachicera & Ulidiidae & 4 & 6 & 123 & 100 & Material tipo: 2 táxones, 2 ejs \\
\hline Nematocera & Anysopodidae & 1 & 3 & 20 & 100 & \\
\hline Nematocera & Bibionidae & 4 & 29 & 436 & 100 & Incluye material afrotropical \\
\hline Nematocera & Cecidomiidae & 3 & 4 & 89 & 100 & \\
\hline Nematocera & Ceratopogonidae & 9 & 15 & 53 & 100 & \\
\hline Nematocera & Chironomidae & 9 & 46 & 155 & 99 & \\
\hline Nematocera & Culicidae & 8 & 89 & 1539 & 93 & Incluye material de Guinea Ecuatorial. Material tipo: 3 táxones, 5 ejs \\
\hline Nematocera & Dixidae & 1 & 3 & 10 & 100 & \\
\hline Nematocera & Lycoriidae & 4 & 25 & 118 & 100 & \\
\hline Nematocera & Psychodidae & 4 & 7 & 214 & 100 & Revisión E. Martínez Ortega \\
\hline Nematocera & Ptychopteridae & 1 & 3 & 16 & 100 & \\
\hline Nematocera & Scatopsidae & 1 & 6 & 44 & 100 & \\
\hline Nematocera & Simuliidae & 2 & 15 & 108 & 60 & \\
\hline Nematocera & Thaumaleidae & $\overline{1}$ & 1 & 2 & 100 & \\
\hline Nematocera & Tipulidae & 34 & 157 & 769 & 80 & Revisión L. Alonso. Material tipo: 8 táxones, 38 ejs \\
\hline Nematocera & Trichoceridae & 1 & 5 & 15 & 100 & \\
\hline Nematocera & Varias & 15 & 45 & 2139 & 80 & $\begin{array}{l}\text { Preparaciones microscópicas de Culicidae y Psychodidae principalmente. } \\
\text { Incluye material de Guinea Ecuatorial }\end{array}$ \\
\hline Brachicera & Miscelánea & - & - & 5558 & 4 & \\
\hline Nematocera & Miscelánea & - & - & 1701 & 3 & \\
\hline Varios & Miscelánea & - & - & 10338 & 0 & $\begin{array}{l}\text { Incluye } 3593 \text { ejemplares ibéricos, } 3824 \text { paleárticos, } 2421 \text { de Canarias } \\
\text { y } 500 \text { no paleárticos }\end{array}$ \\
\hline
\end{tabular}




\section{EPHEMEROPTERA}

Inventario e informatización: El material en seco fue inventariado en 1986, y está pendiente el conservado en fluido. El inventario no ha sido informatizado.

Número de ejemplares: Reúne 289 efemerópteros montados en seco y 9 lotes con material conservado en alcohol.

Ordenación y composición del material: Todo el material se halla reunido en una única colección de fauna paleártica, fundamentalmente formada por ejemplares ibéricos. Entre el material estudiado (un $35 \%$ ) se incluyen especímenes de 5 géneros y 10 especies.

Material pendiente de estudio: Unos 200 ejemplares $(65 \%$ del material en seco) y los lotes de especímenes en alcohol ( 8 lotes con larvas y 1 con adultos, todos ellos de fauna ibérica).

Táxones representados por ejemplares tipo (localizados hasta 1997): No se han registrado ejemplares tipo.

\section{HEMIPTERA}

Inventario e informatización: El inventario es de 1986, quedando pendiente lo conservado en alcohol. El material tipo está informatizado.
Número de ejemplares: Componen la colección 41.360 ejemplares montados en seco. A éstos hay que añadir un número indeterminado de ejemplares integrados en un fondo de 4.296 HemipteraHomoptera pendientes de separación. En cuanto al material en alcohol, se conservan 204 lotes de hemípteros más 262 lotes con ejemplares de los órdenes Hemiptera-Homoptera sin separar.

Ordenación y composición del material: Existen dos grandes colecciones según la procedencia geográfica de los ejemplares: una colección de fauna paleártica, ibérica en su mayor parte, y otra con ejemplares del resto de las áreas geográficas. El número de géneros y ejemplares de estas faunas se resume a continuación.

\begin{tabular}{lcr} 
Fauna & $\mathbf{N}^{\mathbf{0}}$ gén. & \multicolumn{1}{c}{$\mathbf{N}^{\mathbf{0}}$ ejs } \\
\hline Paleártica & 499 & 25.650 \\
No paleártica & 321 & 9.872
\end{tabular}

Entre las dos colecciones se encuentran representados 772 géneros. En la Tabla 5 se facilitan datos sobre la composición geográfica y taxonómica de estas colecciones.

Material pendiente de estudio: Existen 5.838 especímenes sin estudiar, además de los ejemplares pertenecientes a este orden que se hallen en el fondo Hemiptera-Homoptera antes mencionado. Todo el

Tabla 5.- Orden Hemiptera. Composición taxonómica y geográfica.

\begin{tabular}{|c|c|c|c|c|c|c|}
\hline Superfamilia & Familia & Fauna & $N^{\circ}$ gé & $N^{\circ}$ ejs & \%ident. & Observaciones \\
\hline Aradoidea & Varias & Paleártica & 5 & 101 & 90 & \\
\hline Cimicoidea & Anthocoridae & Paleártica & 10 & 222 & 70 & \\
\hline Cimicoidea & Cimicidae & Paleártica & 1 & 7 & 100 & \\
\hline Cimicoidea & Miridae & Paleártica & 127 & 5947 & 60 & Revisión parcial M. Goula \\
\hline Coreoidea & Coreidae & Paleártica & 46 & 2886 & 80 & Coreidae s. ant. Revisión M. A. Vázquez \\
\hline Coreoidea & Coreidae & No paleártica & 57 & 1903 & 60 & Coreidae s. ant. \\
\hline Corixoidea & Corixidae & Paleártica & 7 & 701 & 20 & \\
\hline Gerroidea & Hebridae & Paleártica & 1 & 14 & 100 & \\
\hline Gerroidea & Varias & Paleártica & 5 & 482 & 90 & \\
\hline Lygaeoidea & Berythidae & Paleártica & 7 & 127 & 100 & \\
\hline Lygaeoidea & Lygaeidae & Paleártica & 120 & 5143 & 95 & Lygaeidae $s$. ant. Revisión J. Pericart \\
\hline Lygaeoidea & Lygaeidae & No paleártica & 20 & 1453 & 15 & Incluye material de Guinea Ecuatorial \\
\hline Notonectoidea & Belostomidae & No paleártica & 5 & 196 & 50 & \\
\hline Notonectoidea & Naucoridae & Paleártica & 5 & 124 & 100 & \\
\hline Notonectoidea & Nepidae & Paleártica & 2 & 107 & 80 & \\
\hline Notonectoidea & Nepidae & No paleártica & 4 & 114 & 40 & \\
\hline Notonectoidea & Notonectidae & Paleártica & 3 & 315 & 100 & \\
\hline Pentatomoidea & Pentatomidae & Paleártica & 81 & 5362 & 85 & Pentatomidae s. ant. \\
\hline Pentatomoidea & Pentatomidae & No paleártica & 137 & 4346 & 35 & Pentatomidae s. ant. \\
\hline Reduvioidea & Nabidae & $\begin{array}{l}\text { Paleártica } \\
\text { Pan }\end{array}$ & 5 & 535 & 95 & \\
\hline Reduvioidea & Phymatidae & Mundial & 4 & 91 & 60 & \\
\hline Reduvioidea & Reduviidae & Paleártica & 20 & 1183 & 80 & \\
\hline Reduvioidea & Reduviidae & No paleártica & 88 & 1625 & 60 & \\
\hline Reduvioidea & Saldidae & Paleártica & 10 & 249 & 60 & \\
\hline Tingoidea & Tingidae & Paleártica & 44 & 1484 & 100 & \\
\hline Tingoidea & Tingidae & No paleártica & 6 & 144 & 100 & \\
\hline Varias & Miscelánea & Paleártica & 149 & 4403 & 15 & Fundamentalmente España peninsular y Canarias \\
\hline Varias & Miscelánea & No paleártica & - & 2096 & 0 & $\begin{array}{l}1878 \text { ejemplares de Guinea Ecuatorial procedentes de las } \\
\text { expediciones Peris-Álvarez (1959-61) y Ortiz-Mateu (1948) }\end{array}$ \\
\hline Hemiptera-Homoptera & Miscelánea & Mundial & - & 4296 & 0 & $\begin{array}{l}\text { Fundamentalmente material de Canarias y de la región } \\
\text { afrotropical; } 400 \text { ejemplares de la colección Latreille }\end{array}$ \\
\hline
\end{tabular}


material en alcohol está también pendiente de estudio: 203 lotes de fauna paleártica, 1 de no paleártica y 262 lotes de miscelánea Hemiptera-Homoptera.

Táxones representados por ejemplares tipo (localizados hasta 1997): Se conservan 84 ejemplares tipo de 52 táxones. De entre los 19 especialistas que han descrito estos táxones destacan $\mathrm{H}$. Schouteden (con 9 táxones), I. Bolívar (8) y A. Villiers (6). El material tipo se desglosa por faunas en el siguiente cuadro.

\begin{tabular}{lcc} 
Fauna & Táxones & $\mathbf{N}^{\mathbf{0}}$ ejs \\
\hline Ibérica & 11 & 32 \\
Canarias & 1 & 2 \\
Resto de faunas & 40 & 50
\end{tabular}

Observaciones: Destacan en esta colección las aportaciones de I. Bolívar, C. Chicote, W. L. Distant, A. García Varela, J. Gómez Menor, G.
Horváth y H. Schouteden. Se conserva también una valiosa colección de Hemiptera-Homoptera formada por unos 400 ejemplares, que perteneció a P. A. Latreille; fue adquirida por E. Carreño en París y se recibió en el Museo junto a la colección de este último autor, tras su muerte ocurrida en 1842.

La colección ha sido consultada en los últimos años por M. Baena, M. Costas, J. Deckert, U. Göllner-Scheiding, J. Grazia, A. Kaitala, R. E. Linnavuori, T. López, P. Magnien, M. París, M. P. Reguera del Río.

\section{HOMOPTERA}

Inventario e informatización: Se ha realizado el inventario del material conservado en seco (1986) y de la colección de muestras vegetales (1994). El

Tabla 6.- Orden Homoptera. Composición taxonómica y geográfica.

\begin{tabular}{|c|c|c|c|c|c|c|c|}
\hline Suborden & Superfamilia & Familia & Fauna & $N^{\circ}$ gén. & $N^{\circ}$ ejs & \%ident. & Observaciones \\
\hline Auchenorrhyncha & Cicadoidea & Cercopidae & Paleártica & 12 & 989 & 70 & Material tipo: 1 taxon, 1 ej. \\
\hline Auchenorrhyncha & Cicadoidea & Cercopidae & No paleártica & 19 & 937 & 30 & \\
\hline Auchenorrhyncha & Cicadoidea & Cicadellidae & Paleártica & 54 & 2245 & 80 & Material tipo: 4 táxones, 4 ejs \\
\hline Auchenorrhyncha & Cicadoidea & Cicadidae & Paleártica & 12 & 735 & 35 & \\
\hline Auchenorrhyncha & Cicadoidea & Cicadidae & No paleártica & 54 & 753 & 25 & \\
\hline Auchenorrhyncha & Cicadoidea & Membracidae & Paleártica & 3 & 132 & 20 & Material tipo: 2 táxones, 2 ejs \\
\hline Auchenorrhyncha & Cicadoidea & Membracidae & No paleártica & 64 & 1233 & 65 & Material tipo: 36 táxones, 43 ejs \\
\hline Auchenorrhyncha & Fulgoroidea & Acanalonidae & No paleártica & 2 & 11 & 90 & \\
\hline Auchenorrhyncha & Fulgoroidea & Cixidae & Paleártica & 5 & 208 & 75 & \\
\hline Auchenorrhyncha & Fulgoroidea & Delphacidae & Paleártica & 17 & 318 & 20 & \\
\hline Auchenorrhyncha & Fulgoroidea & Derbidae & No paleártica & & 10 & 0 & \\
\hline Auchenorrhyncha & Fulgoroidea & Dictyopharidae & Paleártica & 2 & 193 & 50 & Material tipo: 6 táxones, 6 ejs \\
\hline Auchenorrhyncha & Fulgoroidea & Flatidae & Paleártica & 2 & 2 & 100 & \\
\hline Auchenorrhyncha & Fulgoroidea & Flatidae & No paleártica & 30 & 193 & 80 & \\
\hline Auchenorrhyncha & Fulgoroidea & Fulgoridae & No paleártica & 29 & 384 & 50 & \\
\hline Auchenorrhyncha & Fulgoroidea & Issidae & Paleártica & 5 & 217 & 60 & \\
\hline Auchenorrhyncha & Fulgoroidea & Ricanidae & No paleártica & 16 & 104 & 100 & \\
\hline Auchenorrhyncha & Fulgoroidea & Tettigometridae & Paleártica & 1 & 220 & 60 & \\
\hline Sternorrhyncha & Aleyrodoidea & Aleyrodidae & Ibérica & - & 225 & 64 & $\begin{array}{l}\text { Revisión E. Hernández. Material tipo: } \\
1 \text { taxon, } 1 \text { ej. }\end{array}$ \\
\hline Sternorrhyncha & Aleyrodoidea & Aleyrodidae & Canarias & - & 74 & 55 & Revisión E. Hernández \\
\hline Sternorrhyncha & Aleyrodoidea & Aleyrodidae & General & - & 40 & 10 & \\
\hline Sternorrhyncha & Aphidoidea & Aphididae & lbérica & - & 412 & 5 & \\
\hline Sternorrhyncha & Aphidoidea & Aphididae & Paleártica & - & 24 & 0 & \\
\hline Sternorrhyncha & Aphidoidea & Aphididae & General & - & 5 & 60 & \\
\hline Sternorrhyncha & Coccoidea & Varias & lbérica & - & 1394 & 81 & $\begin{array}{l}\text { Revisión A. Blay. Material tipo: } 15 \text { táxo- } \\
\text { nes, } 82 \text { ejs }\end{array}$ \\
\hline Sternorrhyncha & Coccoidea & Varias & Canarias & - & 15 & 66 & \\
\hline Sternorrhyncha & Coccoidea & Varias & General & - & 24 & 58 & Material tipo: 2 táxones, 5 ejs \\
\hline Sternorrhyncha & Psylloidea & Psyllidae & lbérica & - & 48 & 10 & \\
\hline Auchenorrhyncha & Varias & Miscelánea & Mundial & 6 & 5600 & 0 & $\begin{array}{l}\text { Fundamentalmente material ibérico; } 976 \\
\text { ejemplares de Guinea Ecuatorial proce } \\
\text { dentes de las expediciones Peris-Álvarez } \\
(1959-61) \text { y Ortiz-Mateu (1948) }\end{array}$ \\
\hline Sternorrhyncha & Varias & Miscelánea & Ibérica & - & 15 & 0 & \\
\hline Hemipt.-Homopt. & Varias & Miscelánea & Mundial & - & 4296 & 0 & $\begin{array}{l}\text { Fundamentalmente material de Canarias } \\
\text { y de la región afrotropical; } 400 \text { ejemplares } \\
\text { de la colección Latreille }\end{array}$ \\
\hline
\end{tabular}


inventario de las preparaciones microscópicas está en curso. Los datos recogidos en los inventarios están en parte informatizados. Resta por inventariar el material conservado en alcohol.

Número de ejemplares: Se conservan 14.484 ejemplares montados en seco, 2.276 preparaciones microscópicas, 237 lotes de material en alcohol y 1.410 muestras vegetales (agallas y muestras de plantas con fitófagos). También existe una miscelánea de Hemiptera-Homoptera sin separar, que incluye 4.296 ejemplares montados en seco y 262 lotes de material en alcohol.

Ordenación y composición del material: El material montado en seco (suborden Auchenorrhyncha) está agrupado en dos grandes colecciones: una con material paleártico, fundamentalmente de fauna ibérica, y otra con material procedente de otras áreas. El número de géneros y ejemplares de estas faunas se resume a continuación.

\begin{tabular}{lcc} 
Fauna & $\mathbf{N}^{\mathbf{0}}$ gén. & $\mathbf{N}^{\mathbf{0}}$ ejs \\
\hline Paleártica & 113 & 8.249 \\
No paleártica & 220 & 5.259
\end{tabular}

Los ejemplares preservados en preparaciones microscópicas (suborden Sternorrhyncha), corresponden a las siguientes áreas geográficas.

\begin{tabular}{lc} 
Fauna & $\mathbf{N}^{\mathbf{0}}$ prep. \\
\hline Ibérica & 2.094 \\
Canarias & 89 \\
General & 93
\end{tabular}

El total de géneros de homópteros recogidos hasta el momento en el inventario es de 374. En la Tabla 6 se facilitan los datos de composición por familias de los dos subórdenes.

Del material en alcohol 95 lotes contienen ejemplares ya estudiados, procedentes en su mayor parte de la Península Ibérica. La información sobre las muestras vegetales se desglosa en el capítulo correspondiente.

Material pendiente de estudio: Hay 5.600 ejemplares, fundamentalmente ibéricos, del suborden Auchenorrhyncha y 15 del suborden Sternorrhyncha, pendientes de separación y estudio; del material conservado en alcohol faltan por estudiar 132 lotes y está pendiente también el fondo HemipteraHomoptera.

Táxones representados por ejemplares tipo (localizados hasta 1997): Se han localizado 144 ejemplares tipo de 67 táxones, descritos por 7 autores. Destacan entre éstos D. Peláez (21) y J. Gómez Menor (15). El material tipo se desglosa por faunas en el siguiente cuadro.

\begin{tabular}{lcr} 
Fauna & Táxones & $\mathbf{N}^{\mathbf{0}}$ ejs \\
\hline Ibérica & 22 & 89 \\
Marruecos & 2 & 2 \\
Guinea Ec. & 12 & 12 \\
General & 31 & 41
\end{tabular}

Observaciones: J. Gómez Menor desarrolló una importante labor en el estudio y composición de este grupo. Se conserva también material de homópteros en la valiosa colección de P. A. Latreille que ya se ha mencionado en el apartado del orden Hemiptera, y material de referencia de V. Lallemand y L. Melichar.

La colección ha sido consultada en los últimos años por D. Aguín Pombo, P. Álvarez López, F. J. Beitia, Y. Ben-Dov, L. L. Deitz, P. Fontana, C. Hodgson, F. Iaccarino, J. H. Martin, D. R. Miller, G. Pellizzari, J. Ramos Aremar, M.Wilson.

\section{HYMENOPTERA}

Inventario e informatización: Hasta el momento se posee inventario de aproximadamente un 53\% del material conservado en seco, del $100 \%$ de las preparaciones microscópicas y del 69\% del material conservado en alcohol. Están informatizados los datos de encírtidos, mutílidos y pteromálidos, así como el material tipo de los grupos inventariados, los tipos localizados en familias no inventariadas y los que ingresan a la colección debido a donaciones.

Número de ejemplares: El número de ejemplares en seco registrados en el inventario es 173.574. A esta cifra hay que añadir alrededor de 150.000 ejemplares que se estima reúne la parte de la colección pendiente del mismo. Hay también 1.148 preparaciones microscópicas y 3.622 lotes de material en alcohol.

Ordenación y composición del material: El material en seco y en preparaciones microscópicas está organizado siguiendo criterios taxonómicos y geográficos, de forma que existen tres colecciones para cada superfamilia o familia: ibérica, Canarias y general. El número total de ejemplares y de géneros recogidos en el inventario se resume por faunas en la tabla siguiente.

\begin{tabular}{lcc} 
Fauna & $\mathbf{N}^{\mathbf{o}}$ gén. & \multicolumn{1}{c}{$\mathbf{N}^{\mathbf{0}}$ ejs } \\
\hline Ibérica & 440 & 97.094 \\
Canarias & 90 & 7.450 \\
General & 510 & 48.510 \\
Mundial & 355 & 21.580
\end{tabular}

El conjunto de lo inventariado alcanza un total de 1.154 géneros representados hasta el momento 


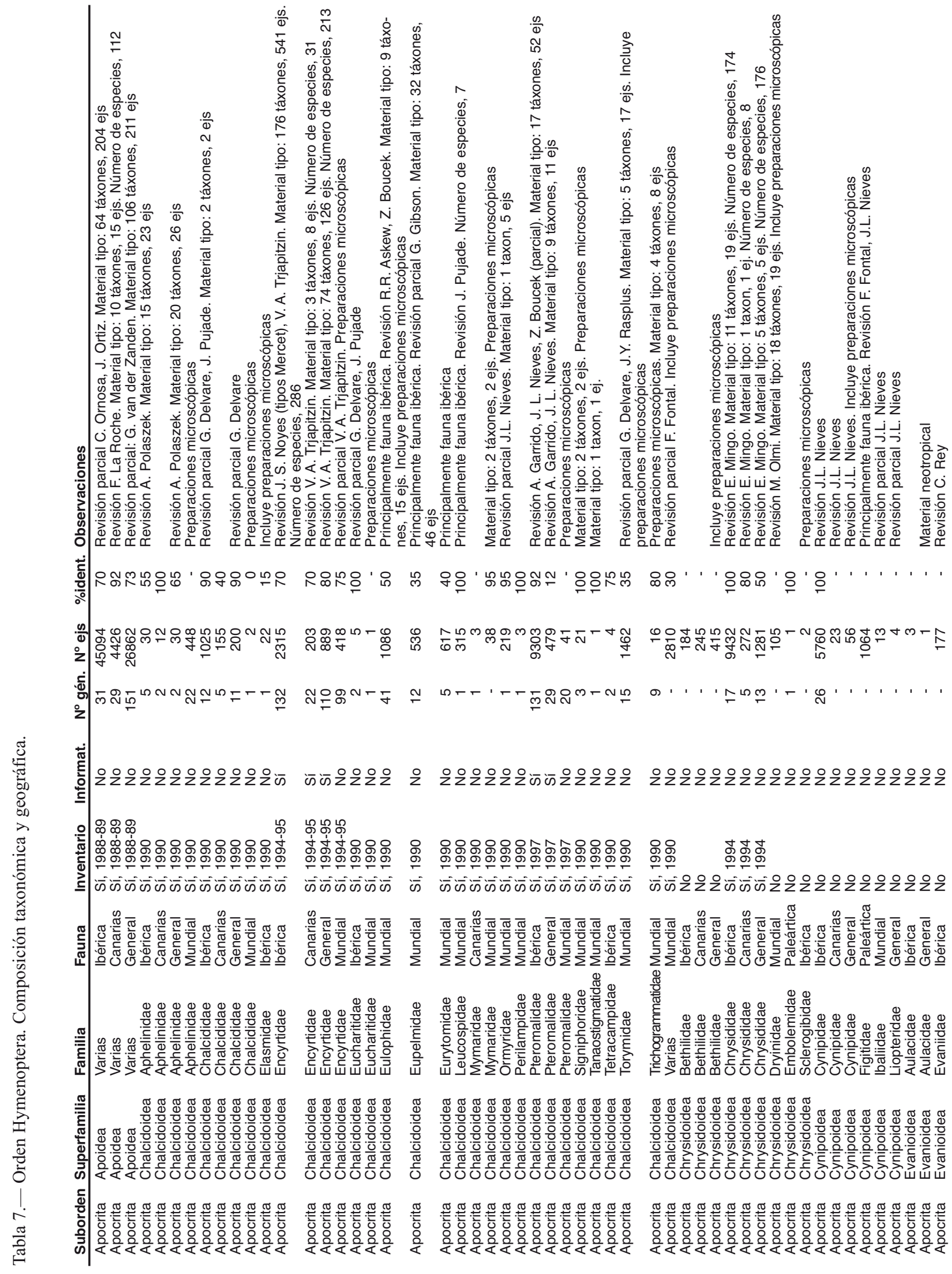




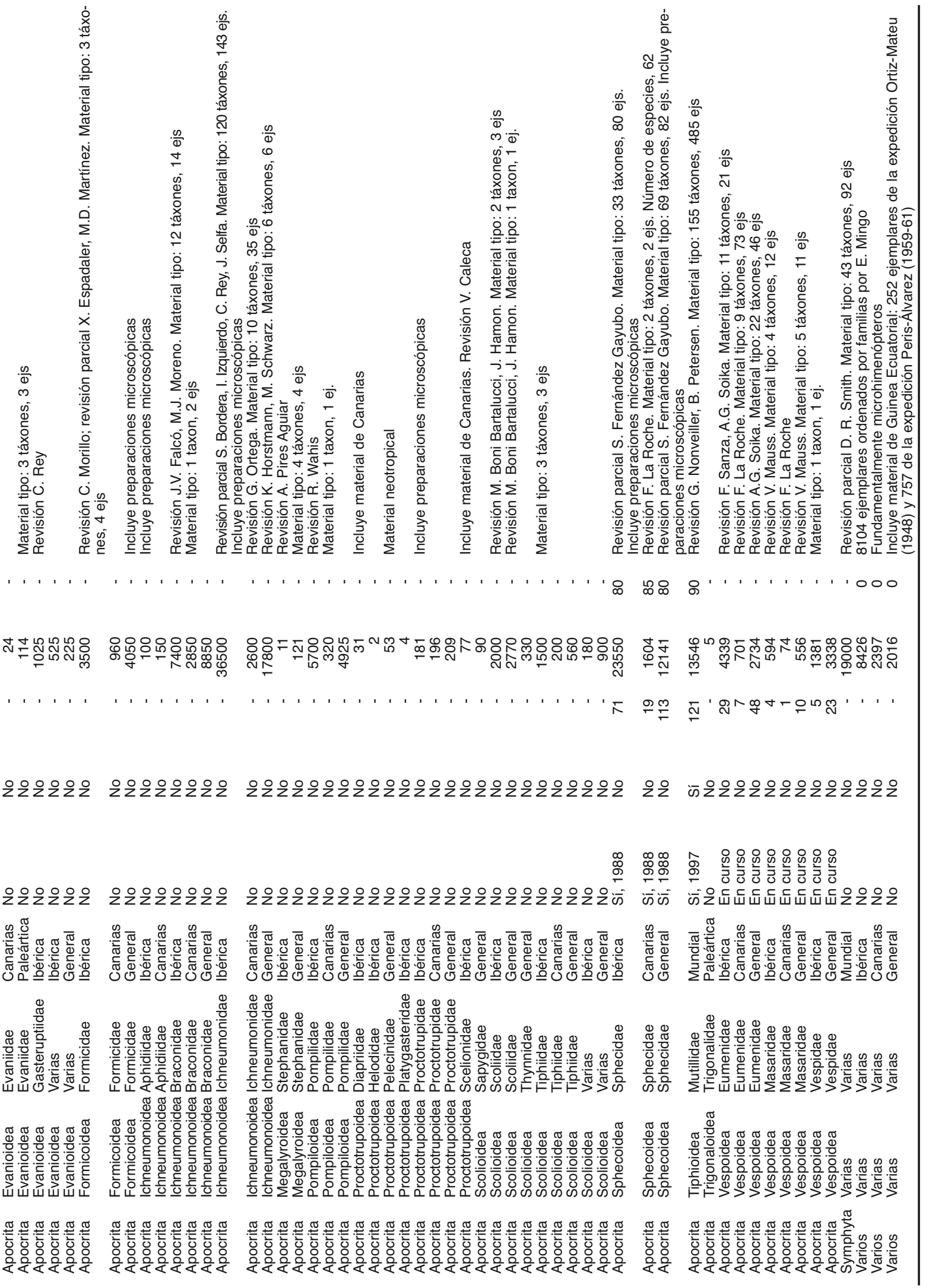


en la colección. Las cifras de géneros y ejemplares y el porcentaje de identificación del material inventariado se desglosan, por familias y faunas, en la Tabla 7. Las cifras estimadas de especímenes para las familias cuyo inventario está por hacer se ofrecen en la misma tabla. El criterio seguido para la agrupación de subórdenes, superfamilias y familias es básicamente el de Gauld \& Bolton (1988).

Se conservan 2.566 lotes de ejemplares ibéricos en alcohol todos ellos estudiados. Existe también una colección de agallas producidas por himenópteros, cuya información se detalla en el apartado Muestras vegetales, y se conservan además 60 nidos de distintas especies y procedencias.

Material pendiente de estudio: Entre el material en seco inventariado hay 15.649 ejemplares sin estudiar. Se conservan también 1.056 lotes con ejemplares en alcohol, 986 de la Península Ibérica, 3 de Canarias, 30 paleárticos y 37 no paleárticos.

Táxones representados por ejemplares tipo (localizados hasta 1997): Se han inventariado 2.769 ejemplares tipo de 1.128 táxones, descritos por 123 autores. Algunos de éstos son R. García Mercet (253), J.M. Dusmet (81), J. Giner Marí (81), F. Suárez (78), A. Seyrig (56), G. Ceballos (50), V. Berthomieu (23), J. Kriechbaumer (22), H. Friese (21), P. Blüthgen (20), J.L. Nieves Aldrey (20), F. Invrea (19), P. H. Timberlake (17), K. Warncke (16) y C. Bolívar Pieltáin (14). El material tipo se desglosa por faunas en el cuadro siguiente.

\begin{tabular}{lcr} 
Fauna & Táxones & $\mathbf{N}^{\mathbf{0}}$ ejs \\
\hline Ibérica & 559 & 1.632 \\
Canarias & 43 & 156 \\
General & 526 & 981
\end{tabular}

Observaciones: Hay que destacar entre el material de este orden las aportaciones, tanto científicas como de material, de J. D. Alfken, V. Berthomieu, P. Blüthgen, C. Bolívar Pieltáin, A. Cabrera, G. Ceballos, J. M. Dusmet, R. Forsius, R. García Mercet, J. Giner Marí, J. Gogorza, J. J. Junco, F. W. Konow, J. Kriechbaumer, P. Lesne, F. Maidl, L. Masi, M. Medina, R. Meyer, E. Mingo, J. Noskiewizc, P. Roth, F. Ruschka, F. Santschi, A. Seyrig, F. J. Suárez, W. Trautmann, J. Vachal.

La colección ha sido consultada en los últimos años por P. Agulló, A. V. Antropov, M. Arnone, J. Banaszak, H. Baur, R. M. Bohart, D. J. Brothers, R. Cambra, L. Castro Torres, G. Evans, L. Fernández Aparicio, F. Fresno, F. García González, R. Gerat, M. J. Gijswijt, V. V. Gorbatovsky, E. Guerrieri, K. Guichard, J. Gusenleitner, R. Hinz, R. Jiménez Peydró, A. J. Jiménez Rodríguez, D. Kasparyan, F.
Koch, F. Luna, M. Made, L. Masner, G. Melik, J. Moreno Marí, A. Müller, M. T. Oltrá, F. J. Ortiz, J. Papp, M. Pavesi, J. J. Pedrero, W. J. Pulawski, D. Quintero Arias, F. Ronquist, J. Sawoniewicz, P. L. Scaramozzino, K. Schmidt, A. W. Skalski, M. J. Sommeijer, M. D. Springate, C. L. Suárez, A. Taeger, M. Terzo, C. Thirion, C. Thueroczy, A. Tinaut, T. Osten, B. Tkalcù, H. Tussac, C. R. Vardy, M. J. Verdú, G. Viggiani, D. Wahl, J. Zwakhals.

\section{ISOPTERA}

Inventario e informatización: El material fue inventariado en 1986 y queda pendiente lo conservado en alcohol. El inventario no está informatizado.

Número de ejemplares: Hay 241 ejemplares procedentes sobre todo de la Península Ibérica y de otras áreas de la región paleártica. El material conservado en alcohol está constituido por 32 lotes.

Ordenación y composición del material: Existe una única colección en la que están representados 3 géneros y 3 especies.

Material pendiente de estudio: El 50\% del material en seco está por estudiar, así como todos los ejemplares conservados en alcohol ( 8 lotes de fauna ibérica, 1 de Canarias y 23 de otras áreas).

Táxones representados por ejemplares tipo (localizados hasta 1997): No se ha registrado hasta ahora ningún ejemplar tipo.

Observaciones: Parte de la colección ha sido revisada por R. Constantino.

\section{LEPIDOPTERA}

Inventario e informatización: El inventario fue efectuado entre 1986 y 1987. Están informatizados los datos de los Tortricidae ibéricos, la colección de genitalias en preparaciones microscópicas y el material tipo. Está pendiente el inventario de los ejemplares conservados en alcohol.

Número de ejemplares: La colección de lepidópteros cuenta con 320.182 ejemplares montados en seco, 9.166 preparaciones microscópicas de genitalias y 424 lotes de material en alcohol (195 de ellos contienen larvas).

Ordenación y composición del material: El material está organizado en diversas colecciones geográficas, ordenadas a su vez taxonómicamente, y una serie de colecciones formadas por lepidopterólogos que trabajaron en el centro o las donaron al mismo. Existen además otras colecciones cuyo objetivo no es estrictamente taxonómico, como las de ciclos biológicos y orugas. 


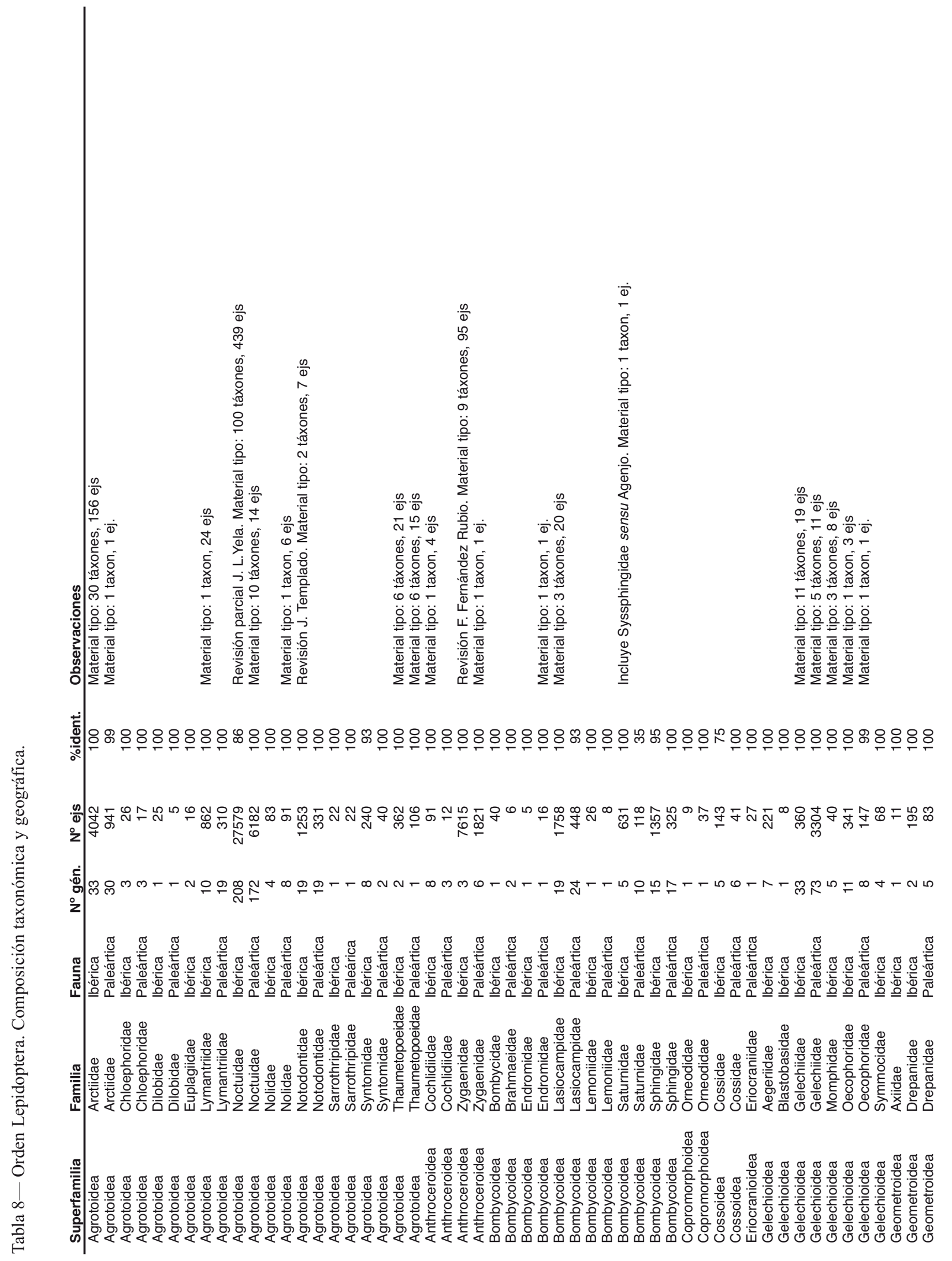




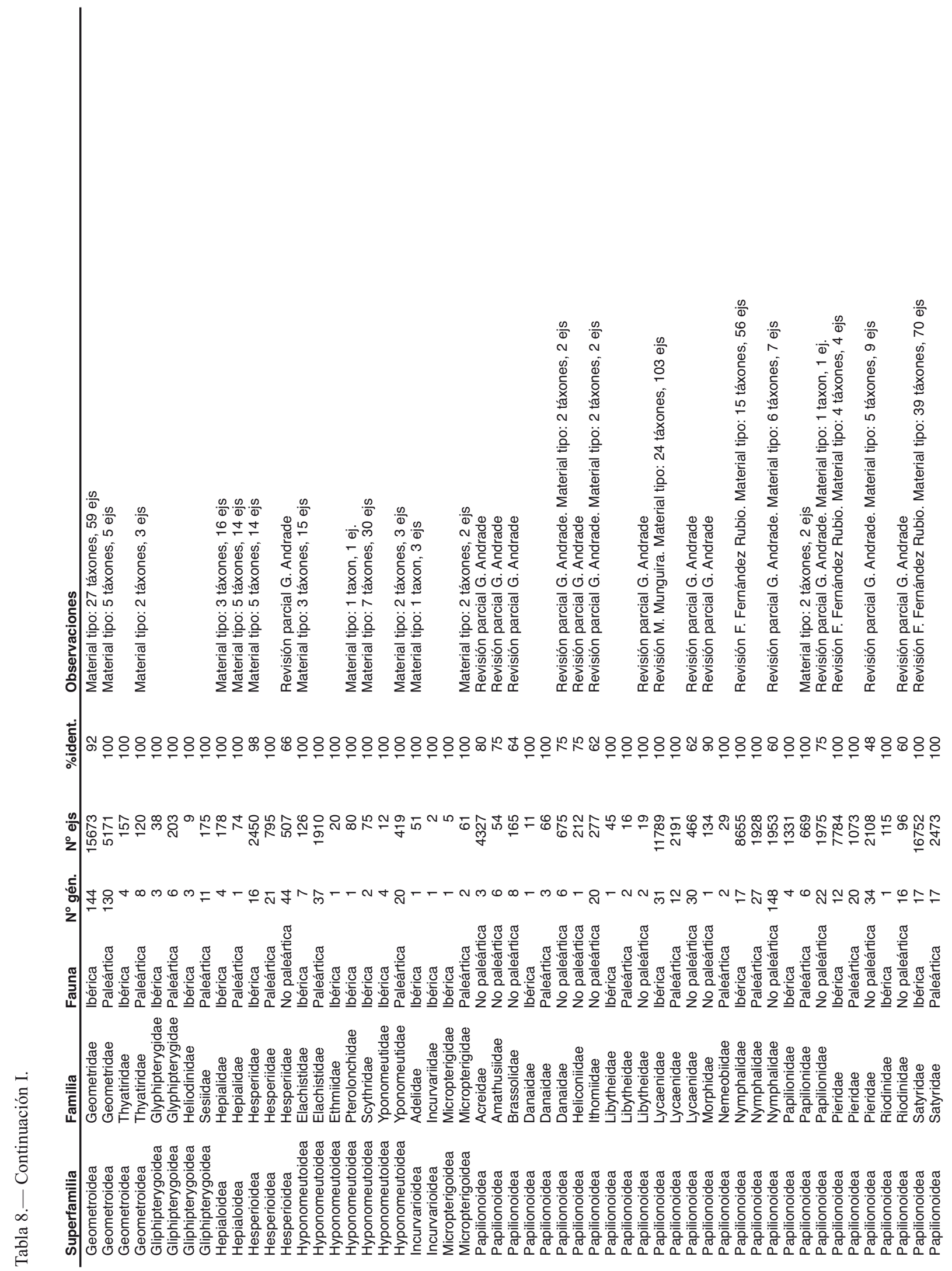




\begin{tabular}{|c|c|c|c|}
\hline 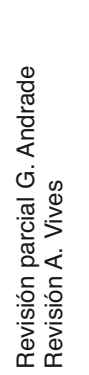 & 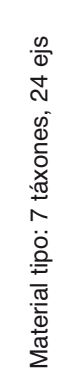 & 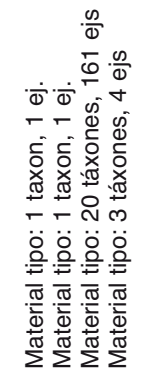 & 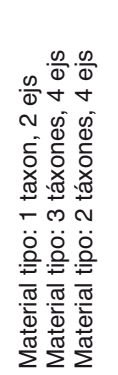 \\
\hline
\end{tabular}

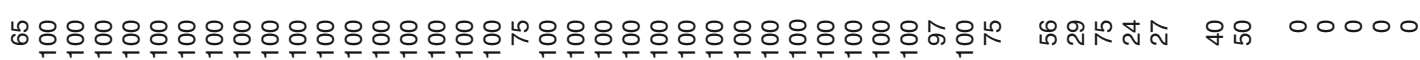

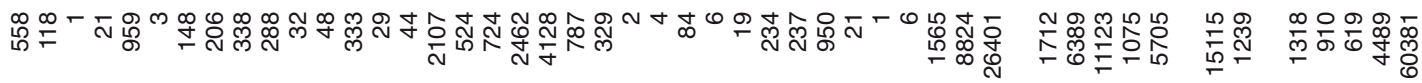

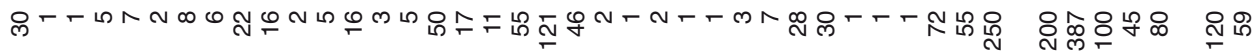

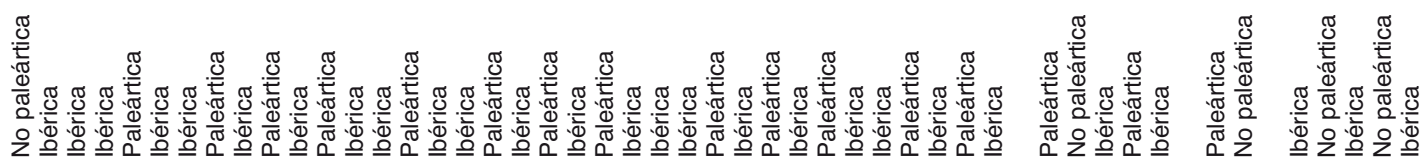

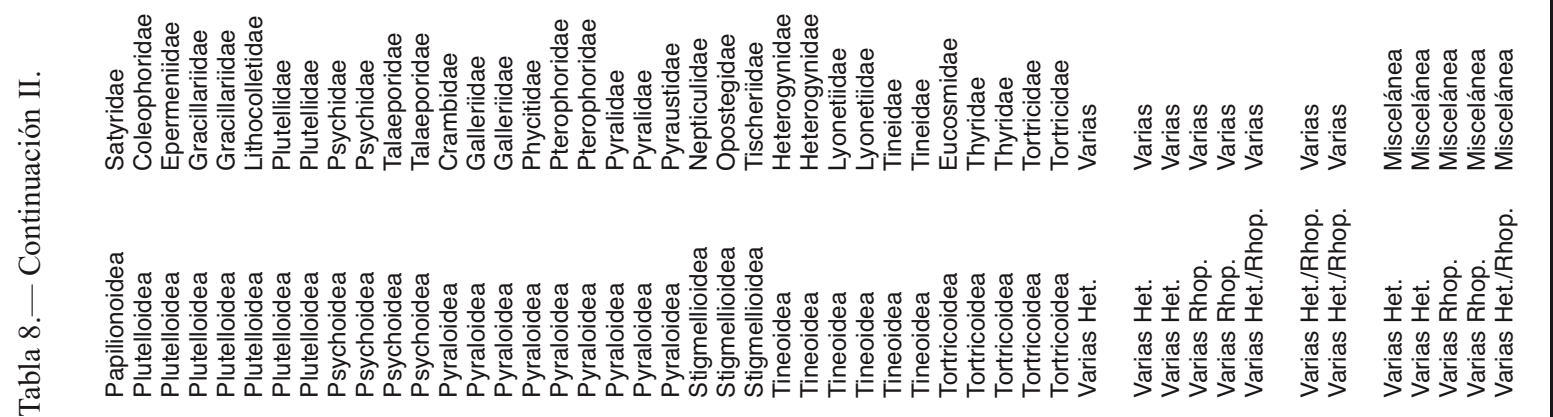


A continuación se detalla el número de ejemplares existentes en total en estas colecciones según el área geográfica de procedencia.

\begin{tabular}{lrcr|r} 
Fauna & Heteróceros & Ropalóceros & Heter./Ropal. & Total \\
\hline Ibérica & 99.092 & 60.055 & 5.705 & 164.852 \\
Paleártica & 41.029 & 10.315 & 15.115 & 66.480 \\
No paleártica & 6.389 & 13.526 & 1.239 & 21.154 \\
\hline Total & 146.510 & 83.896 & 22.059 & 252.465
\end{tabular}

El número total de géneros recogidos en el inventario asciende a 2.556. En la Tabla 8 se facilitan los datos sobre la composición taxonómica y geográfica de este orden; se ha seguido inicialmente el Catálogo ordenador de Agenjo (1946-1977) ya que la ordenación y criterios presentes en la colección son fundamentalmente de este autor. Se ha consultado también a Vives (1994) y Leraut (1980).

Del material en alcohol, se consevan 203 lotes con ejemplares procedentes de la Península Ibérica que están estudiados. Existe una colección de orugas insufladas de gran valor histórico y estético, debida a J. Lauffer. Hay también una colección de agallas y otra que ilustra la relación planta-insecto, cuya información se detalla más adelante en los apartados correspondientes.

Material pendiente de estudio: Quedan 67.717 ejemplares sin estudiar $(92 \%$ se trata de material ibérico) y 221 lotes de material en alcohol.

Táxones representados por ejemplares tipo (localizados hasta 1997): Se han inventariado 1.516 ejemplares tipo de 413 táxones descritos por 70 autores. Entre éstos destacan R. Agenjo (con 226 táxones con material tipo en la colección), A. Fernández (32), I. Sagarra (11), B. J. Lempke (11) y con 10, H. Reisser, C. Rungs y W. Schmidt. El material tipo se desglosa por faunas en el siguiente cuadro.

\begin{tabular}{lcr} 
Fauna & Táxones & $\mathbf{N}^{\mathbf{0}}$ ejs \\
\hline Ibérica & 330 & 1.388 \\
Marruecos & 17 & 27 \\
General & 66 & 101
\end{tabular}

Observaciones: Hay que destacar en esta colección las aportaciones de R. Agenjo, A. Fernández, D. Hospital, M. de Ibarra, N. M. Kheil, M. Koch, G. Pardo de Santayana, F. Poey, M. Pujol, I. Sagarra, I. Sala de Castellarnau, T. Seebold, J. Templado, A. Varea.

La colección ha sido consultada en los últimos años por E. Baraniack, J. Bellavista, J. Cifuentes, R. Citores, J. Dantart, M. Domínguez, D. Dunont, J. M. Ferrin, M. Fibiger, E. García Barros, V. García Villanueva, S. Gaspar, J. Gastón, C. Gómez de Aizpurúa, M. R. Honey, P. Huemer, L. Kaila, A. Kaitala, G. Lamas Müller, J. E. Llorente Bousquets, G. Luquet, J. M. Marcos, J. Martín Cano, A. Masó, M. Matthews, Z. Mészaros, M. Meyer, L. Núñez Vázquez, I. Olano, E. Olivella, A. Ortiz, M. Parentti, M. Pérez Valiente, A. Popescu, A. Prozorov, V. M. Redondo, L. Romera, G. Ronkay, L. Ronkay, M. J. Sanz, K. S. Sattler, P. L. Siguero, C. Silva, A. W. Skalski, M. Stanescu, P. Trematerra, H. Yu-Feng.

\section{MALLOPHAGA}

Inventario e informatización: La colección está pendiente de inventario.

Número de ejemplares: Se conservan 2.728 preparaciones microscópicas con unos 5.000 ejemplares. Ordenación y composición del material: El material de este orden proviene fundamentalmente del área paleártica, existiendo una colección de ejemplares ibéricos y otra para el resto de la región. Los

Tabla 9.- Orden Mallophaga. Composición taxonómica y geográfica.

\begin{tabular}{lllcccc} 
Suborden & Familia & Fauna & $\mathbf{N}^{\circ}$ gén. & $\mathbf{N}^{\circ}$ esp. & N $^{\circ}$ prep. & \%ident. \\
\hline Amblycera & Laemobothriidae & Ibérica & 1 & 5 & 32 & 100 \\
Amblycera & Laemobothriidae & Paleártica & 1 & 3 & 10 & 100 \\
Amblycera & Menoponidae & Ibérica & 16 & 37 & 604 & 100 \\
Amblycera & Menoponidae & Paleártica & 15 & 18 & 71 & 100 \\
Amblycera & Ricinidae & Ibérica & 1 & 4 & 14 & 100 \\
Ischnocera & Philopteridae & Ibérica & 32 & 76 & 927 & 100 \\
Ischnocera & Philopteridae & Paleártica & 25 & 45 & 139 & 100 \\
Ischnocera & Trichodectidae & Ibérica & 5 & 12 & 226 & 100 \\
Ischnocera & Trichodectidae & Paleártica & 2 & 3 & 5 & 100 \\
Amblycera & Miscelánea & - & - & - & 200 & 0 \\
Ischnocera & Miscelánea & - & - & - & 500 & 0 \\
\hline
\end{tabular}


especímenes pertenecen a 134 especies de 55 géneros. El número total de géneros y preparaciones por faunas es el siguiente.

\begin{tabular}{lcc} 
Fauna & $\mathbf{N}^{\mathbf{0}}$ gén. & $\mathbf{N}^{\mathbf{0}}$ prep. \\
\hline Ibérica & 55 & 1.803 \\
Paleártica & 43 & 225
\end{tabular}

En la Tabla 9 se desglosa por familias y faunas el número de géneros, especies, preparaciones y el nivel de identificación.

Material pendiente de estudio: Existen alrededor de 700 preparaciones microscópicas de las familias Philopteridae y Menoponidae (500 y 200 respectivamente) pendientes de estudio.

Táxones representados por ejemplares tipo (localizados hasta 1997): Se conservan 4 especies con material tipo.

Observaciones: La colección ha sido organizada y estudiada por M. P. Martín Mateo y ha sido consultada en los últimos años por R. L. Palma y H. Romera.

\section{MANTODEA}

Inventario e informatización: El inventario del material en seco fue realizado en 1987 y queda pendiente el del conservado en fluido. Los táxones con material tipo están informatizados.

Número de ejemplares: La colección posee 4.523 especímenes montados en seco y 16 lotes con ejemplares preservados en alcohol. Hay también 9 preparaciones microscópicas con estructuras del aparato genital.

Ordenación y composición del material: El criterio de organización del material es geográfico y está agrupado en las siguientes colecciones: fauna ibérica, Canarias, Marruecos, Ifni-Sahara, Guinea Ecuatorial, fauna paleártica y una colección no paleártica que reúne los ejemplares procedentes de las restantes áreas. En el siguiente cuadro aparece reflejado el número de géneros y ejemplares, además del porcentaje del material identificado. El total de géneros representados es 122 .

\begin{tabular}{lrrc} 
Fauna & $\mathbf{N}^{0}$ gén. & $\mathbf{N}^{\mathbf{0}}$ ejs & \% ident. \\
\hline Ibérica & 9 & 1.268 & 93 \\
Canarias & 5 & 116 & 99 \\
Paleártica & 20 & 571 & 99 \\
No paleártica & 118 & 2.568 & 57
\end{tabular}

Material pendiente de estudio: Existen 705 ejemplares sin estudiar, lo que supone un $16 \%$ del total de la colección. El 85\% de este material es de fauna no paleártica. El material en alcohol también está pendiente de estudio.

Táxones representados por ejemplares tipo (localizados hasta 1997): Se conservan 115 ejemplares tipo de 50 táxones descritos por 8 autores. Destacan los táxones descritos por I. Bolívar (27) y L. Chopard (10). El material tipo se desglosa por faunas en el siguiente cuadro.

\begin{tabular}{lcr} 
Fauna & Táxones & $\mathbf{N}^{\mathbf{0}}$ ejs \\
\hline Ibérica & 2 & 6 \\
Marruecos & 10 & 44 \\
Guinea Ec. & 2 & 2 \\
General & 36 & 63
\end{tabular}

Observaciones: La colección reúne un importante material colectado y/o estudiado por I. Bolívar, E. Giglio-Tos y E. Morales Agacino. Ha sido revisada en parte por K. Harz y también consultada en los últimos años por L. M. de Almeida, D. Lombardo, R.Roig, C. Sanz de Bremond.

\section{MECOPTERA}

Inventario e informatización: La colección fue inventariada en 1986. Los datos no están informatizados.

Número de ejemplares: Hay 139 especímenes conservados en seco.

Ordenación y composición del material: El material de este orden está organizado en una única colección, proviniendo una gran parte de los ejemplares de la Península Ibérica. El 80\% de los especímenes está estudiado; están representados 2 géneros y 7 especies.

Material pendiente de estudio: Unos 30 ejemplares están sin estudiar.

Táxones representados por ejemplares tipo (localizados hasta 1997): Se ha registrado material tipo de un solo taxon descrito por L. Navás.

\section{MEGALOPTERA}

Inventario e informatización: El inventario fue realizado en 1986. No está informatizado.

Número de ejemplares: Hay 92 ejemplares conservados en seco y 1 lote preservado en fluido.

Ordenación y composición del material: El material está organizado en una única colección que fundamentalmente es de fauna ibérica. El 90\% de los ejemplares están estudiados, registrándose 6 géneros y 9 especies.

Material pendiente de estudio: 9 especímenes y los ejemplares conservados en alcohol. 
Táxones representados por ejemplares tipo (localizados hasta 1997): No se ha registrado ningún ejemplar tipo.

\section{NEUROPTERA}

Inventario e informatización: El inventario fue llevado a cabo en 1986, quedando pendiente el del material conservado en alcohol. El material tipo está informatizado.

Número de ejemplares: La colección de este orden está constituida por 4.023 ejemplares conservados en seco y 220 lotes en fluido.

Ordenación y composición del material: El material en seco está organizado siguiendo un criterio geográfico: fauna ibérica, paleártica y de otras áreas. Dentro de cada colección geográfica la ordenación es sistemática. El número de géneros y ejemplares se especifica a continuación.

\begin{tabular}{lcr} 
Fauna & $\mathbf{N}^{0}$ gén. & $\mathbf{N}^{\mathbf{0}}$ ejs \\
\hline Ibérica & 43 & 1.991 \\
Paleártica & 33 & 935 \\
No paleártica & 34 & 212
\end{tabular}

El número total de géneros representados es de 73. En la Tabla 10 se muestran algunos datos sobre la composición taxonómica y faunística del material de este orden.

El material conservado en alcohol está agrupado según su procedencia geográfica, estando estudiados 184 lotes de los procedentes de la Península Ibérica, en los que se incluyen 13 especies de la familia Coniopterygidae, 1 de Dilaridae, 9 de Hemerobiidae, 11 de Chrysopidae y 4 de la familia Myrmeleonidae.

Material pendiente de estudio: Existen 885 ejemplares que están sin estudiar, siendo ibérico el $79 \%$ de este material. Entre los especímenes preservados en alcohol hay pendientes de estudio 26 lotes de la Península Ibérica y 10 de otras áreas.

Táxones representados por ejemplares tipo (localizados hasta 1997): Se han localizado 28 ejemplares tipo de 23 táxones, descritos por 4 autores: L. Navás (19), V. J. Monserrat (2), A. Bormans (1) y Bo Tjeder (1).

Observaciones: Hay que destacar en esta colección las aportaciones de F. Klapalek y L. Navás. El material ha sido revisado y ordenado por V. J. Monserrat, y consultado por A. E. González López.

Tabla 10.- Orden Neuroptera. Composición taxonómica y geográfica.

\begin{tabular}{|c|c|c|c|c|c|c|}
\hline Superfamilia & Familia & Fauna & Nº gén. & $N^{\circ}$ ejs & \%ident. & Observaciones \\
\hline Coniopterygoidea & Coniopterygidae & Ibérica & 8 & 16 & 100 & \\
\hline Coniopterygoidea & Coniopterygidae & No paleártica & 1 & 6 & 100 & Material tipo: 2 táxones, 6 ejs \\
\hline Hemerobioidea & Chrysopidae & Ibérica & 4 & 687 & 98 & \\
\hline Hemerobioidea & Chrysopidae & Paleártica & 3 & 86 & 93 & \\
\hline Hemerobioidea & Chrysopidae & No paleártica & 3 & 16 & 70 & Material tipo: 1 taxon, 1 ej. \\
\hline Hemerobioidea & Hemerobiidae & lbérica & 7 & 89 & 100 & \\
\hline Hemerobioidea & Hemerobiidae & Paleártica & 5 & 25 & 86 & \\
\hline Mantispoidea & Dilaridae & Ibérica & 1 & 73 & 100 & Material tipo: 1 taxon, 1 ej. \\
\hline Mantispoidea & Dilaridae & Paleártica & 2 & 6 & 100 & $\begin{array}{l}\text { Incluye familia Sisyridae. Material tipo: } \\
1 \text { taxon, } 3 \text { ejs }\end{array}$ \\
\hline Mantispoidea & Mantispidae & Ibérica & 2 & 28 & 100 & \\
\hline Mantispoidea & Mantispidae & Paleártica & 1 & 2 & 0 & \\
\hline Mantispoidea & Mantispidae & No paleártica & 1 & 30 & 27 & \\
\hline Myrmeleontoidea & Ascalaphidae & Ibérica & 3 & 173 & 100 & \\
\hline Myrmeleontoidea & Ascalaphidae & Paleártica & 5 & 101 & 95 & Material tipo: 1 taxon, 1 ej. \\
\hline Myrmeleontoidea & Ascalaphidae & No paleártica & 6 & 20 & 60 & Material tipo: 4 táxones, 4 ejs \\
\hline Myrmeleontoidea & Myrmeleontidae & Ibérica & 15 & 622 & 100 & \\
\hline Myrmeleontoidea & Myrmeleontidae & Paleártica & 13 & 162 & 75 & Material tipo: 7 táxones, 7 ejs \\
\hline Myrmeleontoidea & Myrmeleontidae & No paleártica & 12 & 49 & 75 & Material tipo: 5 táxones, 5 ejs \\
\hline Myrmeleontoidea & Nemopteridae & Ibérica & 2 & 277 & 100 & \\
\hline Myrmeleontoidea & Nemopteridae & Paleártica & 2 & 94 & 100 & Material tipo: 1 taxon, 1 ej. \\
\hline Myrmeleontoidea & Nemopteridae & No paleártica & 1 & 36 & 100 & \\
\hline Myrmeleontoidea & Psychosidae & No paleártica & 2 & 6 & 50 & \\
\hline Osmyloidea & Osmylidae & lbérica & 1 & 26 & 100 & \\
\hline Osmyloidea & Osmylidae & Paleártica & 1 & 11 & 100 & \\
\hline Varias & Varias & Canarias & 7 & 448 & 15 & \\
\hline Varias & Varias & No paleártica & 8 & 49 & 29 & \\
\hline Varias & Miscelánea & lbérica & - & 701 & 0 & \\
\hline Varias & Miscelánea & Paleártica & - & 184 & 0 & \\
\hline
\end{tabular}




\section{ODONATA}

Inventario e informatización: Se conserva material en seco, cuyo inventario se realizó en 1986, y material en alcohol del que no se posee inventario. Número de ejemplares: Esta colección cuenta con 6.670 ejemplares montados en seco y 36 lotes con larvas en alcohol.

Ordenación y composición del material: El material en seco, ya estudiado, lo constituyen 5.121 ejemplares organizados en tres colecciones geográficas: ibérica, paleártica y no paleártica; en ésta última se incluye numeroso material de Guinea Ecuatorial. Su composición en número de géneros y ejemplares se resume en la tabla siguiente.

\begin{tabular}{lcc} 
Fauna & $\mathbf{N}^{\mathbf{0}}$ gén. & $\mathbf{N}^{\mathbf{0}} \mathbf{e j s}$ \\
\hline Ibérica & 28 & 3.024 \\
Paleártica & 36 & 334 \\
No paleártica & 130 & 1.763
\end{tabular}

Los datos relativos a la composición taxonómica se desglosan en la Tabla 11. En total se han registrado 134 géneros de este orden. De los lotes de alcohol, 30 corresponden a material ibérico estudiado.

Material pendiente de estudio: Hay una miscelánea de 1.549 ejemplares en seco pendientes de estu- dio y separación: 528 ibéricos, 22 paleárticos y 999 de otras faunas. También están sin estudiar 6 lotes de larvas en alcohol.

Táxones representados por ejemplares tipo (localizados hasta 1997): Se han localizado 14 ejemplares tipo de 14 táxones descritos por tres autores, A. Compte (9), R. Martin (4) y F. J. Ocharán (1).

Observaciones: Esta colección contiene un importante material estudiado $\mathrm{y} / \mathrm{o}$ colectado por $\mathrm{R}$. Martin y M. E. Selys-Longchamps. La colección de material ibérico está siendo revisada en la actualidad por A. Compte.

\section{ORTHOPTERA}

Inventario e informatización: El inventario fue realizado en 1987 y está pendiente el del material conservado en alcohol. Los táxones con material tipo están informatizados.

Número de ejemplares: Se conservan 101.743 ejemplares montados en seco, 385 lotes preservados en alcohol y 91 preparaciones microscópicas de estructuras genitales.

Ordenación y composición del material: El criterio de organización del material es geográfico y está agrupado en las siguientes colecciones: fauna

Tabla 11.- Orden Odonata. Composición taxonómica y geográfica.

\begin{tabular}{|c|c|c|c|c|c|c|}
\hline Suborden & Familia & Fauna & $N^{\circ}$ gén. & $N^{\circ}$ ejs & \%ident. & Observaciones \\
\hline Anisoptera & Aeschnidae & Ibérica & 5 & 185 & 95 & Revisión A. Compte \\
\hline Anisoptera & Aeschnidae & Paleártica & 6 & 44 & 85 & Incluye material de Canarias \\
\hline Anisoptera & Aeschnidae & No paleártica & 10 & 98 & 90 & Incluye material de Guinea Ecuatorial \\
\hline Anisoptera & Cordulegasteridae & Ibérica & 1 & 126 & 90 & Revisión A. Compte \\
\hline Anisoptera & Cordulegasteridae & No Ibérica & 3 & 6 & 100 & \\
\hline Anisoptera & Gomphidae & Ibérica & 3 & 166 & 100 & Revisión A. Compte \\
\hline Anisoptera & Gomphidae & Paleártica & 4 & 30 & 75 & \\
\hline Anisoptera & Gomphidae & No paleártica & 8 & 13 & 50 & \\
\hline Anisoptera & Libellulidae & Ibérica & 9 & 970 & 95 & Revisión A. Compte \\
\hline Anisoptera & Libellulidae & Paleártica & 12 & 191 & 97 & \\
\hline Anisoptera & Libellulidae & No paleártica & 58 & 909 & 60 & Incluye material de Guinea Ecuatorial \\
\hline Zygoptera & Calopterigidae & lbérica & 4 & 348 & 80 & Revisión A. Compte \\
\hline Zygoptera & Calopterigidae & Paleártica & 4 & 87 & 90 & Incluye material de Canarias \\
\hline Zygoptera & Calopterigidae & No paleártica & 17 & 389 & 75 & Incluye material de Guinea Ecuatorial \\
\hline Zygoptera & Coenagrionidae & lbérica & 7 & 782 & 98 & Revisión A. Compte \\
\hline Zygoptera & Coenagrionidae & Paleártica & 7 & 69 & 70 & Incluye material de Canarias \\
\hline Zygoptera & Coenagrionidae & No paleártica & 16 & 185 & 50 & \\
\hline Zygoptera & Lestidae & Ibérica & 2 & 447 & 100 & Revisión A. Compte \\
\hline Zygoptera & Lestidae & Paleártica & 2 & 91 & 85 & \\
\hline Zygoptera & Lestidae & No paleártica & 8 & 62 & 50 & \\
\hline Zygoptera & Megapodagriidae & No paleártica & 1 & 2 & 100 & Material de Guinea Ecuatorial \\
\hline Zygoptera & Protoneuridae & No paleártica & 1 & 19 & 100 & Material de Guinea Ecuatorial \\
\hline Zygoptera & Pseudostigmatidae & No paleártica & 3 & 6 & 100 & \\
\hline Zygopt./Anisopt. & Varias & Neotropical & 18 & 80 & 95 & $\begin{array}{l}\text { Material de Coiba (Panamá). Revisión A. Compte. } \\
\text { Número de especies, } 26\end{array}$ \\
\hline Zygopt./Anisopt. & Miscelánea & Ibérica & - & 528 & 0 & \\
\hline Zygopt./Anisopt. & Miscelánea & Paleártica & 3 & 22 & 30 & Incluye material de Canarias \\
\hline Zygopt./Anisopt. & Miscelánea & No paleártica & 3 & 999 & 3 & Incluye material de Guinea Ecuatorial \\
\hline
\end{tabular}


Tabla 12.- Orden Orthoptera. Composición taxonómica y geográfica.

\begin{tabular}{|c|c|c|c|c|c|c|}
\hline Suborden & Superfamilia & Fauna & $N^{\circ}$ gén. & $\mathrm{N}^{\circ}$ ejs & \%ident. & Observaciones \\
\hline Caelifera & Acridoidea (Pamphagidae) & Ibérica & 7 & 1451 & 100 & Revisión M. La Greca, V. Llorente \\
\hline Caelifera & Acridoidea (Pyrgomorphidae) & Ibérica & 1 & 223 & 100 & Revisión parcial V. Llorente \\
\hline Caelifera & Acridoidea (otras familias) & Ibérica & 47 & 25557 & 90 & Revisión E. Clemente, J. J. Presa \\
\hline Caelifera & Acridoidea & Canarias & 18 & 3016 & 90 & \\
\hline Caelifera & Acridoidea & Paleártica & 107 & 11286 & 95 & Incluye material de Marruecos \\
\hline Caelifera & Acridoidea & Madagascar & 73 & 3518 & 100 & \\
\hline Caelifera & Acridoidea & No paleártica & 585 & 15219 & 80 & $\begin{array}{l}\text { Incluye material de Guinea Ecuatorial e } \\
\text { Ifni Sahara }\end{array}$ \\
\hline Caelifera & Tetrigoidea & Ibérica & 3 & 736 & 100 & Revisión V. Llorente, J. J. Presa \\
\hline Caelifera & Tetrigoidea & Canarias & 1 & 144 & 100 & \\
\hline Caelifera & Tetrigoidea & Paleártica & 3 & 375 & 100 & Incluye material de Marruecos \\
\hline Caelifera & Tetrigoidea & No paleártica & 100 & 2451 & 60 & Incluye material de Guinea Ecuatorial \\
\hline Caelifera & Varias & Ibérica & - & 3626 & 100 & Revisión V. Llorente \\
\hline Ensifera & Grylloidea & Ibérica & 15 & 2000 & 100 & Revisión A.V. Gorochov, V. Llorente \\
\hline Ensifera & Grylloidea & Canarias & 7 & 357 & 100 & Revisión A.V. Gorochov, V. Llorente \\
\hline Ensifera & Grylloidea & Paleártica & 28 & 2598 & 100 & Incluye material de Marruecos \\
\hline Ensifera & Grylloidea & No paleártica & 99 & 2659 & 50 & $\begin{array}{l}\text { Incluye material de Guinea Ecuatorial e } \\
\text { Ifni Sahara }\end{array}$ \\
\hline Ensifera & Gryllotalpoidea & Ibérica & 1 & 70 & 100 & \\
\hline Ensifera & Gryllotalpoidea & Paleártica & 1 & 56 & 100 & Incluye material de Marruecos y Canarias \\
\hline Ensifera & Gryllotalpoidea & No paleártica & 5 & 156 & 70 & $\begin{array}{l}\text { Incluye material de Guinea Ecuatorial e } \\
\text { Ifni Sahara }\end{array}$ \\
\hline Ensifera & Rhaphidophoroidea & Ibérica & 1 & 53 & 100 & \\
\hline Ensifera & Tettigonioidea & Ibérica & 41 & 7601 & 99 & $\begin{array}{l}\text { Revisión parcial A. Galvagni, V. Llorente, } \\
\text { M. V. Peinado, C. Pinedo }\end{array}$ \\
\hline Ensifera & Tettigonioidea & Canarias & 10 & 312 & 100 & Revisión parcial C. Pinedo \\
\hline Ensifera & Tettigonioidea & Paleártica & 71 & 2547 & 99 & \\
\hline Ensifera & Tettigonioidea & No paleártica & 311 & 5319 & 85 & \\
\hline Ensifera & Varias & lbérica & - & 249 & 100 & Revisión V. Llorente \\
\hline Ensifera/Caelifera & Miscelánea & Ibérica & - & 676 & 0 & \\
\hline Ensifera/Caelifera & Miscelánea & Canarias & - & 73 & 0 & \\
\hline Ensifera/Caelifera & Miscelánea & Marruecos & - & 97 & 0 & \\
\hline Ensifera/Caelifera & Miscelánea & No paleártica & - & 9318 & 0 & \\
\hline
\end{tabular}

ibérica, Canarias, Marruecos, Ifni-Sahara, Guinea Ecuatorial, fauna paleártica y una colección no paleártica que reúne los ejemplares procedentes de las restantes áreas. Cada una de estas colecciones geográficas está ordenada taxonómicamente. Se desglosa a continuación el número de ejemplares, por suborden y fauna, del material ya estudiado.

\begin{tabular}{lcc} 
& \multicolumn{2}{c}{$\mathbf{N}^{\mathbf{0}}$ ejs } \\
\cline { 2 - 3 } Fauna & Caelifera & Ensifera \\
\hline Ibérica & 31.593 & 9.973 \\
Canarias & 3.160 & 669 \\
Paleártica & 11.661 & 5.201 \\
No paleártica & 21.188 & 8.134
\end{tabular}

Se encuentran representados 1.413 géneros. En la Tabla 12 se facilitan datos sobre la composición de esta colección según su ordenación taxonómica y faunística. Del material en alcohol están estudiados sólo 7 lotes (1 de fauna ibérica y 6 de fauna paleártica).

Material pendiente de estudio: Alrededor de un $14 \%$ del total de ejemplares de este orden (10.164) están sin estudiar: 676 ibéricos, 73 canarios, 97 paleárticos y 9.318 de otras áreas. Existen también 378 lotes en alcohol en esta situación (28 de fauna ibérica, 7 de Canarias, 10 de la zona paleártica y 333 de otras regiones).

Táxones representados por ejemplares tipo (localizados hasta 1997): Se han registrado hasta la fecha 4.277 ejemplares tipo de 1.159 táxones descritos por 67 autores. Más de la mitad de estos táxones fueron descritos por I. Bolívar (723). Entre el resto de los autores, los más representados son M. Descamps (43), C. Bolívar Pieltáin (39), E. Morales Agacino (31) y B. P. Uvarov (27). El material tipo se desglosa por familias en el cuadro de la página siguiente.

Observaciones: La colección fue formada básicamente por I. Bolívar, y contiene además importantes contribuciones científicas y de material de J. Almeida Fernández, G. Y. Bey-Bienko, C. Bolívar Pieltáin, M. Cazurro, L. Chopard, M. Descamps, V. M. Dirsh, M. Donskoff, H. Gadeau, K. Harz, D. Hollis, D. K. McE. Kevan, K. H. L. Key, V. Llorente, E. Morales Agacino, L. Navás, D. R. Ragge, D. C. F. Rentz, B. P. Uvarov, C. Willemse. 


\begin{tabular}{llrr} 
Suborden & Familia & Táxones & $\mathbf{N}^{\mathbf{0}}$ ejs \\
\hline Caelifera & Acrididae & 363 & 1.529 \\
Caelifera & Eumastacidae & 109 & 277 \\
Caelifera & Oedipodidae & 2 & 2 \\
Caelifera & Pamphagidae & 40 & 290 \\
Caelifera & Pyrgomorphidae & 99 & 284 \\
Caelifera & Tetrigidae & 117 & 293 \\
Caelifera & Tridactylidae & 2 & 20 \\
Caelifera & Trigonopterygidae & 5 & 9 \\
Caelifera & Truxalidae & 4 & 6 \\
Ensifera & Bradiporidae & 51 & 253 \\
Ensifera & Conocephalidae & 27 & 50 \\
Ensifera & Eneopteridae & 13 & 21 \\
Ensifera & Gryllacrididae & 18 & 27 \\
Ensifera & Gryllidae & 79 & 577 \\
Ensifera & Meconematidae & 24 & 44 \\
Ensifera & Mecopodidae & 1 & 1 \\
Ensifera & Mogoplistidae & 9 & 30 \\
Ensifera & Pentacentridae & 1 & 1 \\
Ensifera & Phalangopsidae & 7 & 10 \\
Ensifera & Phaneropteridae & 49 & 191 \\
Ensifera & Pseudophyllidae & 45 & 75 \\
Ensifera & Pteroplistidae & 1 & 1 \\
Ensifera & Rhaphidophoridae & 6 & 28 \\
Ensifera & Stenopelmatidae & 1 & 1 \\
Ensifera & Tettigoniidae & 76 & 230 \\
Ensifera & Trigonidiidae & 10 & 27
\end{tabular}

La colección ha sido consultada en los últimos años por P. D. Brock, A. Camousseight, L. Dessutter-Grandcolas, H. Devriese, L. Fishelson, S. K. Gangwere, R. Gómez Ladrón de Guevara, J. P. Grunshaw, K. K. Günther, S. Ingrisch, N. D. Jago, F. J. Jeremías Torruela, F. Molino, A. Nadig, P. Naskrecki, D. Otte, J. E. Pardo González, F. Pascual, H. K. Pfau, M. L. Pulido, E. Rebollo, J. Rey Rochas, M. Ritchie, G. H. Schmidt, F. Willemse.

\section{PHASMOPTERA}

Inventario e informatización: La colección fue inventariada en 1987. El material tipo está informatizado.

Número de ejemplares: Se conservan 2.366 ejemplares conservados en seco.

Ordenación y composición del material: El criterio de organización del material es geográfico y está agrupado en las siguientes colecciones: fauna ibérica, Canarias, Marruecos, Ifni-Sahara, Guinea Ecuatorial, fauna paleártica y una colección no paleártica que reúne los ejemplares procedentes de las restantes áreas. Cada una de estas colecciones geográficas está ordenada sistemáticamente. En el cuadro siguiente se desglosa el número de géneros y ejemplares, y porcentaje de identifición del material. El total de géneros representados es 110 .

\begin{tabular}{|lrrr|} 
Fauna & $\mathbf{N}^{\mathbf{0}}$ gén. & $\mathbf{N}^{\mathbf{0}}$ ejs & \% ident. \\
\hline Ibérica & 3 & 491 & 95 \\
Paleártica & 5 & 56 & 100 \\
No paleártica & 106 & 1.593 & 60
\end{tabular}

Material pendiente de estudio: Existe un 10\% de la colección (226 especímenes) sin estudiar, siendo la mayor parte de áreas no pertenecientes a la región paleártica.

Táxones representados por ejemplares tipo (localizados hasta 1997): Se han inventariado 79 ejemplares tipo de 53 táxones, que han sido descritos por J. Redtenbacher (26), C. Brunner (14), I. Bolívar (12) y J. Pantel (1). El material tipo se desglosa por faunas en el cuadro siguiente.

\begin{tabular}{lcc} 
Fauna & Táxones & $\mathbf{N}^{\mathbf{0}}$ ejs \\
\hline Ibérica & 2 & 11 \\
General & 51 & 68
\end{tabular}

Observaciones: La colección contiene importantes aportaciones de I. Bolívar y E. Morales Agacino. La colección paleártica ha sido revisada por $\mathrm{K}$. Harz, y ha sido consultada en los últimos años por P. del Estal y G. Nascetti.

\section{PLECOPTERA}

Inventario e informatización: En 1986 se realizó el inventario del material conservado en seco y está pendiente el del conservado en alcohol.

Número de ejemplares: Se conservan 359 ejemplares en seco y 16 lotes en alcohol.

Ordenación y composición del material: El material en seco está organizado en una única colección ordenada taxonómicamente. Los especímenes provienen fundamentalmente de la Península Ibérica y otras áreas de la región paleártica, estando representados 12 géneros. Los ejemplares preservados en fluido ya estudiados (2 lotes) han sido recolectados en la zona paleártica.

Material pendiente de estudio: El 50\% del material en seco no está identificado, ni tampoco 14 lotes de larvas y adultos de la Península Ibérica conservados en fluido.

Táxones representados por ejemplares tipo (localizados hasta 1997): No se han localizado táxones con material tipo en esta colección.

\section{PROTURA}

El material de este orden está pendiente de inventario. Existe una colección de material en alcohol, pendiente de estudio, que consta de 121 lotes de material ibérico, 6 de Canarias y 2 de la región paleártica. 


\section{PSOCOPTERA}

Inventario e informatización: El inventario del material en seco se realizó en 1986, quedando por realizar el del material conservado en fluido. El inventario no está informatizado.

Número de ejemplares: Se conservan 204 especímenes montados en seco y 558 lotes en alcohol.

Ordenación y composición del material: La colección de material en seco reúne ejemplares de fauna paleártica, fundamentalmente ibéricos. Se tienen representantes de 13 géneros. Del material en alcohol, están estudiados 124 lotes con especímenes ibéricos, que reúnen unas 17 especies.

Material pendiente de estudio: El $10 \%$ de los ejemplares en seco no están identificados. Del material conservado en alcohol restan también por estudiar 393 lotes de fauna ibérica, 3 de Canarias y 38 de otras regiones.

Táxones representados por ejemplares tipo (localizados hasta 1997): Se ha localizado un ejemplar tipo de una especie de Canarias, descrita por Enderlaing.

\section{RAPHIDIOPTERA}

Inventario e informatización: El inventario del material en seco fue realizado en 1986 y no está inventariado el conservado en alcohol. El inventario no está informatizado.

Número de ejemplares: Hay 82 ejemplares montados en seco y 12 lotes de material conservado en alcohol.

Ordenación y composición del material: Los ejemplares están organizados en una única colección de fauna paleártica (material sobre todo ibérico) identificada al 100\%; hay representantes de 6 géneros y 21 especies. Existen además 9 lotes de especímenes en alcohol ya estudiados.

Material pendiente de estudio: 2 lotes con ejemplares ibéricos y 1 con material paleártico están sin estudiar.

Táxones representados por ejemplares tipo (localizados hasta 1997): Se han localizado 5 ejemplares tipo de 5 táxones procedentes de la Península Ibérica, descritos por tres autores, $\mathrm{H}$. Aspöck, U. Aspöck y L. Navás.

\section{SIPHONAPTERA}

Inventario e informatización: El material en seco fue inventariado en 1986 y está pendiente el material conservado en fluido. El inventario no está informatizado.
Número de ejemplares: Existen 549 preparaciones microscópicas y 6 lotes de material en alcohol. Ordenación y composición del material: Las 549 preparaciones microscópicas están reunidas en una única colección que contiene ejemplares de fauna paleártica. Están representados 31 géneros.

Material pendiente de estudio: Alrededor de un $10 \%$ de la colección (56 preparaciones) está sin estudiar. También resta por estudiar el material en alcohol. Táxones representados por ejemplares tipo (localizados hasta 1997): No se han registrado ejemplares tipo.

\section{STREPSIPTERA}

El material de este orden está pendiente de inventario. Existen 13 lotes de fauna ibérica conservados en alcohol.

\section{THYSANOPTERA}

Inventario e informatización: El material en seco fue inventariado en 1997. Los datos no están informatizados. Quedan por inventariar los lotes conservados en alcohol.

Número de ejemplares: Hay 50 ejemplares montados en seco y 412 lotes conservados en fluido.

Ordenación y composición del material: El material en seco está reunido en una única colección que incluye fundamentalmente ejemplares de la fauna ibérica. Los ejemplares en alcohol provienen de la Península Ibérica (410 lotes) y otras áreas de la región paleártica (2 lotes).

Material pendiente de estudio: Todos los ejemplares están sin identificar.

Táxones representados por ejemplares tipo (localizados hasta 1997): No se ha registrado material tipo de este orden.

\section{THYSANURA (MICROCORYPHIA Y ZYGEN- TOMA)}

Gran parte del material está actualmente en revisión por C. Bach (Universidad Autónoma de Barcelona) y M. Gaju (Universidad de Córdoba); este material incluye 231 ejemplares, que están conservados en alcohol o montados en preparaciones microscópicas. Existen también 64 ejemplares conservados en seco y 64 lotes de material en alcohol (60 de fauna ibérica y 4 de Canarias), que están pendientes de estudio e inventario.

Táxones representados por ejemplares tipo (localizados hasta 1997): Se han localizado 58 
Tabla 13.- Orden Trichoptera. Composición taxonómica y geográfica.

\begin{tabular}{|c|c|c|c|c|c|c|}
\hline Superfamilia & Familia & Fauna & $\mathrm{N}^{\circ}$ gén. & $N^{\circ}$ ejs & \%ident. & Observaciones \\
\hline Hydropsychoidea & Hydropsychidae & Ibérica & 6 & 74 & 60 & Material tipo: 3 táxones, 3 ejs \\
\hline Limnephiloidea & Leptoceridae & Ibérica & 7 & 33 & 95 & Material tipo: 1 taxon, 1 ej. \\
\hline Limnephiloidea & Limnephilidae & Ibérica & 12 & 1026 & 20 & Material tipo: 3 táxones, 4 ejs \\
\hline Limnephiloidea & Sericostomidae & Ibérica & 9 & 67 & 90 & Material tipo: 2 táxones, 2 ejs \\
\hline Limnephiloidea & Phryganeidae & No paleártica & 1 & 2 & 100 & \\
\hline Rhyacophiloidea & Rhyacophilidae & Ibérica & 2 & 120 & 10 & \\
\hline Varias & Varias & Ibérica & 5 & 252 & 10 & \\
\hline Varias & Varias & Paleártica & 17 & 158 & 15 & Material tipo: 3 táxones, 4 ejs \\
\hline
\end{tabular}

ejemplares tipo de 8 táxones descritos por cinco autores, C. Bach, M. Gaju, R. García Becerra, R. Molero Baltanás y A. Tinaut.

\section{TRICHOPTERA}

Inventario e informatización: El inventario del material en seco fue realizado en 1986; no está informatizado. Queda pendiente el inventario del material en alcohol.

Número de ejemplares: La colección en seco contiene 1.732 ejemplares y la de alcohol 80 lotes.

Ordenación y composición del material: La colección en seco está ordenada taxonómicamente y la mayor parte del material procede de la Península Ibérica. Hay 60 lotes de material en alcohol, que están estudiados e incluyen 18 especies. En la Tabla 13 se facilitan datos sobre la composición taxonómica y faunística de la colección.

Material pendiente de estudio: Una gran parte del material en seco está sin estudiar, así como 20 lotes de material en alcohol.

Táxones representados por ejemplares tipo (localizados hasta 1997): Se han localizado 14 ejemplares tipo de 12 táxones descritos por cuatro autores, G. Enderlein, M. E. Mosely, L. Navás y F. Schmid.

Observaciones: El material está revisado por R. Vera y, más recientemente, por M. A. González y J. C. Iglesias. La colección ha sido consultada por F. Cobo Gradín.

\section{Colección general de alcohol}

La colección de material en alcohol reúne 15.102 lotes de insectos, resultantes de muestreos de procedencia y finalidad muy diversa, que presentan niveles de separación e identificación muy poco homogéneos; en unos casos la ordenación es taxonómica $\mathrm{y}$, en otros, se mantienen reunidos los lotes que proceden de un mismo muestreo. Existe un inventario que recoge el número de lotes que integran este material, pero que no incluye el número de ejemplares contenidos en los mismos.

Colección taxonómica. Reúne 13.868 lotes (10\% identificados). Las cifras de lotes por órdenes se resumen en la tabla siguiente.

\begin{tabular}{lrrlr} 
Orden & $\mathbf{N}^{\mathbf{0}}$ lotes & & Orden & $\mathbf{N}^{\mathbf{0}}$ lotes \\
\hline Blattaria & 66 & & Megaloptera & 1 \\
Coleoptera & 804 & & Neuroptera & 220 \\
Collembola & 2.312 & & Odonata & 36 \\
Dermaptera & 52 & & Orthoptera & 385 \\
Diplura & 19 & & Plecoptera & 16 \\
Diptera & 694 & & Protura & 129 \\
Embioptera & 16 & & Psocoptera & 558 \\
Ephemeroptera & 9 & & Raphidioptera & 12 \\
Hemiptera & 204 & & Siphonaptera & 6 \\
Homoptera & 237 & & Strepsiptera & 13 \\
Hem/Hom & 262 & & Thysanoptera & 412 \\
Hymenoptera & 3.622 & & Thysanura & 64 \\
Isoptera & 32 & & Trichoptera & 80 \\
Lepidoptera & 424 & & Miscelánea & 3.167 \\
Mantodea & 16 & & &
\end{tabular}

Muestras vegetales. Existen 108 lotes de fauna ibérica y 12 de otras faunas.

Fauna edáfica. Hay 1.073 lotes casi exclusivamente de fauna ibérica.

Fauna cavernícola. Existen 41 lotes de fauna ibérica.

\section{Colección de muestras vegetales en seco}

Incluye dos colecciones, una de agallas y otra de muestras de plantas con fitófagos.

Colección de agallas. Se conservan 862 muestras con agallas organizadas en dos colecciones, una formada a principios de siglo por J. Cogolludo y otra actualmente por J.L. Nieves. El organismo productor de las agallas está identificado en el $84 \%$ de las 
muestras. El 19\% son agallas de invertebrados no insectos. Los datos de este material están en proceso de informatización. El número de muestras, según el orden del organismo productor y la fauna a la que pertenece se da en el cuadro siguiente.

\begin{tabular}{lllr} 
Orden & Fam/Subfam. & Fauna & $\mathbf{N}^{\mathbf{0}}$ muestras \\
\hline Coleoptera & Apionidae & Ibérica & 2 \\
Coleoptera & Cerambycidae & Ibérica & 2 \\
Coleoptera & Curculionidae & Ibérica & 6 \\
Coleoptera & Scolytidae & Ibérica & 2 \\
Coleoptera & Sin identificar & Ibérica & 1 \\
Diptera & Cecidomyiidae & Ibérica & 136 \\
Diptera & Cecidomyiidae & Paleártica & 2 \\
Diptera & Muscidae & Ibérica & 3 \\
Diptera & Tephritidae & Ibérica & 1 \\
Diptera & Sin identificar & Ibérica & 2 \\
Hemiptera & Tingidae & Ibérica & 3 \\
Homoptera & Adelgidae & Ibérica & 1 \\
Homoptera & Aphidoidea & Ibérica & 87 \\
Homoptera & Psyllidae & Ibérica & 17 \\
Homoptera & Sin identificar & Ibérica & 2 \\
Hymenoptera & Cynipoidea & Ibérica & 253 \\
Hymenoptera & Cynipoidea & Paleártica & 137 \\
Hymenoptera & Cynipoidea & General & 1 \\
Hymenoptera & Tenthredinidae & Ibérica & 17 \\
Hymenoptera & Sin identificar & Ibérica & 6 \\
Lepidoptera & Elachistidae & Ibérica & 2 \\
Lepidoptera & Pterophoridae & Ibérica & 1 \\
Lepidoptera & Tortricidae & Ibérica & 8 \\
Lepidoptera & Sin identificar & Ibérica & 2 \\
Acarina & Eriophyoidea & Ibérica & 161 \\
Acarina & Sin identificar & Ibérica & 1 \\
Nematoda & Angullidae & Ibérica & 4 \\
Nematoda & Sin identificar & Ibérica & 2 \\
\hline & & &
\end{tabular}

Muestras de plantas con fitófagos. Se conservan 1.303 muestras de plantas atacadas por especies de homópteros (fundamentalmente ibéricas) del suborden Sternorrhyncha, de las cuales el $66 \%$ están identificadas. El número de muestras por táxones se reseña en la tabla siguiente.

\begin{tabular}{llrr} 
Superfamilia & Familia & $\mathbf{N}^{\mathbf{0}}$ muestras & \% ident. \\
\hline Aleyrodoidea & Aleyrodidae & 47 & 98 \\
Aphidoidea & Aphididae & 10 & 100 \\
Coccoidea & Asterolecaniidae & 3 & 0 \\
Coccoidea & Coccidae & 234 & 96 \\
Coccoidea & Diaspididae & 372 & 100 \\
Coccoidea & Eriococcidaae & 7 & 100 \\
Coccoidea & Margarodidae & 3 & 33 \\
Coccoidea & Pseudococcidae & 5 & 100 \\
Varias & Varias & 176 & 97 \\
Varias & Miscelánea & 446 & 0
\end{tabular}

\section{Colección de insectos asociados a comunidades vegeta-} les y cultivos

Se reúne bajo este epígrafe una colección realizada por J. Templado como resultado de investiga- ciones sobre biología y ecología de insectos, en la que se ilustra la entomofauna relacionada con diversas especies de árboles y plantas de cultivo. El número de ejemplares por órdenes es el que sigue.

\begin{tabular}{lr} 
Orden & $\mathbf{N}^{\mathbf{0}}$ ejs \\
\hline Coleoptera & 2.895 \\
Dermaptera & 47 \\
Diptera & 404 \\
Ephemeroptera & 1 \\
Hemiptera & 361 \\
Homoptera & 115 \\
Hymenoptera & 250 \\
Lepidoptera & 1.780 \\
Neuroptera & 3 \\
Orthoptera & 9 \\
Raphidioptera & 1 \\
Trichoptera & 4 \\
Miscelánea & 1.262
\end{tabular}

Además de estos ejemplares, la colección incluye muestras vegetales (agallas, troncos y cortezas de árboles atacadas por insectos y plantas cultivadas con fitófagos), capullos de crisálidas y puparios.

\section{Colecciones didácticas}

Se mantienen como colecciones didácticas los ejemplares seleccionados para exposiciones y que ilustran temas específicos como sistemática, ecosistemas madrileños, sistemas fluviales, insectos perjudiciales y beneficiosos, ciclos biológicos, etc. También se consideran en este apartado los ejemplares sin datos de captura que, al carecer de utilidad en las colecciones científicas, se destinan a usos educativos. El primer grupo incluye 3.871 especímenes y el segundo reúne 3.453 ejemplares en seco y 433 lotes en alcohol.

\section{Material pendiente de incorporación}

Este apartado reúne material ingresado recientemente y que aún no está incorporado en su ubicación definitiva, y material recolectado por personal del centro durante el desarrollo de proyectos científicos y que aún no forman parte de la colección.

Material de ingreso reciente. Corresponde principalmente a colecciones recibidas por donación, muestreos aislados e ingresos puntuales o debidos a circunstancias no habituales. Se encuentran en esta situación 27.760 ejemplares de todos los órdenes, montados en seco, y 372 sobres con lepidópteros pendientes de preparación. Las cifras de ejemplares se desglosan por órdenes en el siguiente cuadro. 


\begin{tabular}{lr} 
Orden & $\mathbf{N}^{\mathbf{0}}$ ejs \\
\hline Coleoptera & 10.668 \\
Diptera & 1.670 \\
Hemiptera (s.l.) & 1.670 \\
Hymenoptera & 3.099 \\
Lepidoptera & 8.824 \\
Odonata & 788 \\
Orthoptera (s.l.) & 1.357 \\
Varios & 56
\end{tabular}

Material pendiente de ingreso. Se estima que 2.791.984 ejemplares se encuentran en esta situación; en la siguiente tabla se han desglosado por órdenes.

\begin{tabular}{lr} 
Orden & $\mathbf{N}^{\mathbf{0}}$ ejs \\
\hline Apterygota & 147 \\
Coleoptera & 27.220 \\
Dermaptera & 317 \\
Dictyoptera & 160 \\
Diptera & 600.797 \\
Hemiptera & 2.529 \\
Homoptera & 29.538 \\
Hymenoptera & 107.190 \\
Isoptera & 14 \\
Lepidoptera & 19.341 \\
Neuroptera & 498 \\
Odonata & 82 \\
Orthoptera & 259 \\
Plecoptera & 823 \\
Psocoptera & 371 \\
Strepsiptera & 9 \\
Thysanoptera & 2.493 \\
Trichoptera & 160 \\
Varios & 2.000 .000
\end{tabular}

\section{Disponibilidad de la colección}

La Colección de Entomología es de carácter público y por lo tanto está disponible para su utilización científica y didáctica por parte de los diferentes sectores de la sociedad. Los usos más comunes son:

- Consultas de material en el Centro. Entomólogos profesionales y aficionados pueden hacer consultas del material con fines científicos en el propio centro, con tan sólo solicitar su visita con suficiente antelación, indicando el grupo de insectos en el que están interesados, el objetivo de su consulta y las fechas en las que desean hacerla.

- Préstamo de especímenes. El préstamo de material para estudio puede ser solicitado por entomólogos profesionales o aficionados; en este último caso deberán hacerlo a través de una institución de carácter público (universidades, museos, centros de investigación...) que se responsabilice del material prestado y garantice que el estudio se realizará en sus propias instalaciones. El periodo de los préstamos suele oscilar entre 6 meses y un año. El número de ejem- plares se determina dependiendo fundamentalmente de la representación del taxon en la colección y los objetivos del estudio que se propone el solicitante. Las condiciones generales de préstamo, que figuran en los formularios de envío del material, se pueden consultar también en la Normativa de Colecciones que se incluye en este volumen.

- Información científica y técnica. Se puede solicitar información sobre temas muy variados relacionados con la colección, ya sea de carácter estrictamente científico (existencia de un determinado material en la colección, datos de captura u otros) o técnico (métodos de conservación, control de plagas, gestión, etc.). Se realizan informes científicos y técnicos para empresas y particulares, o bien se ofrece la posibilidad de contacto con la institución, organismo o persona adecuada, en aquellos casos que no puedan ser resueltos a través de personal o medios de este Museo. Se informa también sobre aspectos muy variados relacionados con la Entomología (direcciones de especialistas y asociaciones, técnicas y elementos de conservación, proveedores...).

- Colaboración en exposiciones. Las entidades públicas o privadas pueden solicitar especímenes y útiles entomológicos para su exhibición, pudiéndoseles prestar también asesoramiento temático y expositivo relativo a este material. La participación del Museo debe ser tramitada con la suficiente antelación, dirigiendo una carta a la Dirección del Centro e indicando los datos básicos de la exposición (ver la Normativa de Colecciones).

- Cooperación con centros de enseñanza interesados en ampliar temas de Zoología u otras disciplinas en relación con el mundo de los insectos.

- Otras actividades, como participación en cursos y conferencias, atención a consultas recibidas de particulares, empresas y medios de comunicación, reproducción de fondos de la colección para fines diversos, etc.

Por otra parte, la colección está abierta a las colaboraciones más diversas dirigidas al desarrollo de ésta en múltiples aspectos. Figuran entre estas colaboraciones las donaciones, depósitos e intercambios de material, así como el trabajo personal.

- Se reciben donaciones de especímenes de muy diferentes procedencias, desde ejemplares aislados hasta colecciones completas y tanto de profesionales como de aficionados. Las donaciones de material tipo tienen especial interés para el Centro. Una relación de donantes y de material tipo ingresado por esta vía, puede consultarse en los últimos volúmenes de la revista Eos. 
- Se aceptan depósitos de especímenes y colecciones, aunque no es ésta una vía habitual de ingreso de ejemplares. Las condiciones del depósito se acuerdan entre el depositario, usualmente una institución oficial, y el Museo.

- Por supuesto, es especialmente bienvenida la cooperación de aquellos especialistas interesados en colaborar con la colección a cualquier nivel y en cualquier línea de investigación o apoyo; se agradece especialmente su aportación en la revisión científica y la actualización de la nomenclatura de los grupos de su especialidad, la separación e identificación del material pendiente de estudio o la reorganización de las colecciones. De igual manera se acepta personal voluntario que desee ayudar realizando labores de apoyo a las múltiples tareas derivadas del uso y gestión diario de la colección; se ofrece como contraprestación su preparación en este área. Este personal figura como Voluntario de la Sociedad de Amigos del MNCN y disfruta de las ventajas derivadas de ello.

Forma de acceso. Toda persona interesada en acceder a la colección puede dirigirse a las conservadoras de la misma. La dirección de contacto es:

Isabel Izquierdo / Carolina Martín

Colección de Entomología

Museo Nacional de Ciencias Naturales

C/ José Gutiérrez Abascal, 2

28006 Madrid

Tfno.: 914111328 / 915618607 extensión 1104

Fax: 915645078

Correo electrónico:

Isabel Izquierdo: izquierdo@mncn.csic.es

Carolina Martín: cmartin@mncn.csic.es

El horario de atención es de 9:00 a 15:00, de lunes a viernes. Se recomienda llamar o escribir previamente a una visita, para indicar el objeto y la fecha de la misma.

\section{Objetivos}

Con la triple finalidad de incrementar el valor de la colección en sus diferentes vertientes, agilizar su gestión y facilitar el acceso a la misma, nos proponemos los siguientes objetivos:

1. Concluir el inventario de la totalidad de los fondos.

2. Incluir en bases informáticas los datos de los inventarios iniciales, sólo recogidos hasta ahora en archivos manuales.
3. Completar la colección en lo referente a la fauna ibérica, procurando la representación de todas las especies de insectos existentes en ella.

4. Dar a conocer el contenido de la colección, sobre todo el material tipo depositado, mediante la edición de catálogos y su inclusión en redes informáticas.

5. Reunir una base bibliográfica que contenga todas aquellas publicaciones generadas tras el estudio del material o en las que figuren citados fondos de esta colección.

\section{AGRADECIMIENTOS}

Todo el personal del Museo que trabaja en la planta de Entomología ha contribuido de una u otra forma a hacer posible el presente estudio: M.A. Alonso Zarazaga, M. Coca, A. Compte, F. Fontal, M.L. Hinojosa, M. Hitado, V. Llorente, I. Marcos, M.P. Martín Mateo, F. Martín Piera, J. Miguel Lobo, J.L. Nieves, A. Sánchez Ruiz, M. Sánchez Ruiz, A. Sánchez Terrón, I. Sanmartín y F. Tordesillas. En cualquier caso, estos datos no hubieran podido estar disponibles si los distintos equipos contratados a través de los convenios INEM-CSIC no hubieran realizado con tanta eficacia como entusiasmo la tarea, aún inconclusa, de recoger durante más de 10 años los datos de miles y miles de ejemplares de la colección. Las personas integrantes del último equipo (G. Barbero, M.E. Durán, M. Esteban y E. Sánchez) han extraído, además, información y datos concretos para este trabajo, así como los voluntarios y objetores de conciencia que actualmente se encuentran colaborando con la colección (J. Hortal, C. Jado, R. Franco, J. M. Leonarte y G. Rodríguez). De forma especial queremos agradecer a A. Camacho, así como al resto del Comité Editor de Graellsia, la inagotable paciencia demostrada para con esta memoria; sin su interés tampoco habría sido posible la publicación de nuestro trabajo.

\section{Referencias}

Agenjo, R., 1946-1977. Catálogo ordenador de los lepidópteros de España. Graellsia, varios volúmenes, sin paginar.

Agenjo, R., 1952. Fauna lepidopterológica almeriense. CSIC. Madrid. 370 pp.

BArreiro, A.J., 1992. El Museo Nacional de Ciencias Naturales (1771-1935). Doce Calles. Madrid. 509 pp.

Dusmet Alonso, J.M., 1918. Apuntes para la historia de la entomología en España. Asoc. Esp. Progr. Cienc. (Congreso de Sevilla). Sección 4ª: 205-284.

Dusmet Alonso, J.M., 1919. Apuntes para la historia de la entomología en España. Bol. Soc. Entomol. Esp., 2: 74-84, 87-98, 161-195.

Dusmet Alonso, J.M., 1944. Recuerdos para contribuir a la Historia de la Entomología en España. (Discurso). Real Academia de Ciencias Exactas, Físicas y Naturales Madrid. 94 pp. 
Gauld, I. \& Bolton, B. (eds.), 1988. The hymenoptera. British Museum (Natural History) \& Oxford University Press. New York. 332 pp.

Jordana, R., Arbea, J.I. \& Ariño, A.H., 1990. Catálogo de Colémbolos ibéricos. Base de datos. Public. Biol. Univ. Navarra, Ser. Zool., 21: 1-231.

Jordana, R., Arbea, J.I., Simón, C. \& Luciáñez, M.J. 1997. Collembola, Poduromorpha. En: Fauna Ibérica, vol. 8. Ramos, M.A. et al. (eds.). Museo Nacional de Ciencias Naturales, CSIC. Madrid. 807 pp.

Lawrence, J.F. \& Newton, A.F., 1995. Families and subfamilies of Coleoptera (with selected genera, notes, references and data on family-group names). En: J. Pakaluk and S.A. Slipinski (eds.). Biology, Phylogeny, and Classification of Coleoptera: Papers Celebrating the 80th Birthday of Roy A. Crowson. Muzeum i Instytut Zoologii PAN. Varsovia: 7791092.

LERAUT, P., 1980. Liste systématique et synonymique des lépidoptères de France, Belgique et Corse. Supplément à Alexanor et au Bull. Soc. Entomol. France. 334 pp.

Martín Albaladejo, C., 1994. Bibliografia entomológica de autores españoles (1758-1990). Documentos Fauna Ibérica, 1. Ramos, M.A. (ed.). Museo Nacional de Ciencias Naturales, CSIC. Madrid. 822 pp.

Vives, A., 1994. Catálogo sistemático y sinonímico de los lepidópteros de la Península Ibérica y Baleares (Insecta: Lepidoptera). Ministerio de Agricultura, Pesca y Alimentación. Madrid. X + 775 pp.
Fuentes MANUSCRITAS DEL ARCHIVO DEL MUSEO Nacional de Ciencias Naturales (AMNCN):

- Libro de entradas y salidas de los objetos de las Colecciones de Entomología (1877-1911).

- Libro de entradas del Laboratorio de Entomología (1910) ( noviembre 1910-enero 1922).

- Libro de salidas. Mineralogía, Entomología y Vertebrados (1904-1914).

- Diario I. Laboratorio de Entomología (1923 a 1925).

- Diario II. Laboratorio de Entomología (1925 y 1926).

- Diario. Laboratorio de Entomología. (1933, 1934 y 1935).

\section{Apéndice}

A continuación se listan algunos de los catálogos y trabajos elaborados sobre material depositado en la colección de Entomología; han sido recogidos fundamentalmente de Martín Albaladejo (1994) y los índices de las revistas Eos, Graellsia y las publicaciones de la Real Sociedad Española de Historia Natural.

Agenjo, R., 1937. Los Procris no españoles del Museo de Madrid (Lep. Zygaen.). Eos, 13: 45-116.

Agenjo, R., 1953. Geometridae españoles de la colección D. Hospital, de Barcelona (Lep. Geom.). Eos, 29: 289-328, láms. 10-11.

ANDREU RuBio, J.M., 1959. Bombílidos marroquíes del Instituto Español de Entomología (Diptera). Eos, 35: 7-19.

BACH, C., 1977. Ampliación de conocimientos sobre los Machilida, a través del estudio de una colección del Instituto Español de Entomología (Thysanura). Graellsia, 33: 237-246.

Báguena Corella, L., 1941. Fauna de Coleópteros de los territorios españoles del Golfo de Guinea. Bol. Soc. Esp. Hist. Nat., 39: 67-83, 161-179, 209-229, 261-280.

Báguena Corella, L., 1960. Los Donaciinae ibéricos de la colección del Instituto Español de Entomología (Col. Chrysomelidae). Graellsia, 18: 3-14.
Báguena Corella, L. \& Breuning, S., 1962. Catálogo de los Cerambycidae de las provincias españolas del Golfo de Guinea (Coleoptera). Graellsia, 19: 137-228.

Bolívar, I., 1886. Noticia sobre la colección de coleópteros del Sr. D. Laureano Pérez Arcas, donada generosamente al Museo de Madrid. Actas Soc. Esp. Hist. Nat., 15: 55-60.

Bolívar, I., 1888. Correciones sobre algunas especies de fásmidos existentes en el Museo de Madrid. Actas Soc. Esp. Hist. Nat., 17: 57-59 pág.

Bolívar, I., 1889. Enumeración de los Grílidos de Filipinas. An. Soc. Esp. Hist. Nat., 18: 415-431.

Bolívar, I., 1879. Hemípteros nuevos del Museo de Madrid. An. Soc. Esp. Hist. Nat., 8: 133-146.

Bolívar, I., 1881. Nuevas especies de Ortópteros americanos del viaje al Pacífico. An. Soc. Esp. Hist. Nat., 10: 477-499.

Bolívar, I., 1884. Artrópodos del Viaje al Pacifico, verificado de 1862 a 1865, por una comisión de naturalistas (Insectos 
Neurópteros y Ortópteros). Imprenta de Miguel Ginesta. Madrid. $120 \mathrm{pp}$.

BONET, F., 1929. Colémbolos cavernícolas de España. Eos, 5: 5-32.

Ceballos, G., 1925. Revisión de los Gelis del Museo de Madrid (Hym. Ichneum.). Eos, 1: 133-198.

Ceballos, G., 1926. Estefánidos del Museo de Madrid (Hym. Stephan.). Eos, 2: 135-147, láms. 4.

Ceballos, G., 1927. Anteoninos del Museo de Madrid (Hym. Bethylidae). Eos, 3: 97-109.

Ceballos, G., 1927. Notas sobre Icneumónidos. Gelis de la Colección del Museo de Madrid. Eos, 3: 269-278.

Ceballos, G., 1945. Los Banchini de la Colección del Instituto Español de Entomología (Hymenopt. Ichmeumonidae) Eos, 21: 73-82, lám. 1.

Coвos, A., 1959. Estudios sobre Bupréstidos de la fauna etiópica. II. Nueva contribución al conocimiento de las especies de la Guinea española e isla de Fernando Póo: Cazas del Dr. L. Báguena. Eos, 35: 133-170.

Cogolludo, J., 1921. Contribución al conocimiento de las zoocecidias de España. Trab. Mus. Nac. Cienc. Nat. Madrid (Ser. Bot.), 16: 1-117.

Compte SART, A. 1962. Resultados de la expedición PerisAlvarez a la isla de Annobón. 11. Odonata. Bol. R. Soc. Esp. Hist. Nat. (Secc. Biol.), 60: 35-54.

D’OrBignY, H., 1903. Onthophagus du Cap San Juan. Mem. Soc. Esp. Hist. Nat., 1: 125-127.

Dusmet, J.M., 1915. Algunos Apidos nuevos o interesantes del Museo de Madrid. Trab. Mus. Nac. Cienc. Nat. Madrid (Ser. Zool.), 22: 1-18.

Dusmet, J.M., 1924. Las Xylocopa (Hymen., Apidae) en las Colecciones de Madrid. Trab. Mus. Nac. Cienc. Nat. Madrid (Ser. Zool.), 49: 1-58.

EsCALERA, M.M. de la, 1924. Enumeración de las especies españolas de Dorcadion (Col., Ceramb.) del Museo de Madrid, y descripción de algunas formas nuevas. Bol. R. Soc. Esp. Hist. Nat., 24: 191-200.

GARCÍA FresCA, A., 1923. Malófagos del Museo de Madrid. I. Descripción de una especie nueva de Philopterus. Bol. R. Soc. Esp. Hist. Nat., 23: 196-199.

García Fresca, A., 1923. Malófagos del Museo de Madrid. Segunda nota. Bol. R. Soc. Esp. Hist. Nat., 23: 246-294.

García FrescA, A., 1924. Malófagos del Museo de Madrid. III. Un Tricodéctido nuevo. Bol. R. Soc. Esp. Hist. Nat., 24: 75-78.

García Fresca, A., 1924. Malófagos del Museo de Madrid. IV. Notas sobre Ricinus. Bol. R. Soc. Esp. Hist. Nat., 24: 274-276.

Garrido, A.M. \& Nieves Aldrey, J.L., 1996. Revisión de las especies de pteromálidos descritas por R. García Mercet (Hymenoptera, Chalcidoidea: Pteromalidae). Bol. Asoc. Esp. Entomol., 20(1-2): 221-235

Gil Collado, J., 1919. Sírfidos de Marruecos del Museo de Madrid (Dipt. Syrph.). Mem. R. Soc. Esp. Hist. Nat., 12: 403-415.

Gil Collado, J., 1928. Círtidos nuevos del Museo de Madrid (Dipt.). Eos, 4: 57-64.

GIL Collado, J., 1929. Círtidos españoles y marroquíes del Museo de Madrid (Dipt. Cyrt.). Mem. R. Soc. Esp. Hist. Nat., 15: 539-552.
Gil Collado, J., 1932. Notas sobre Pupíparos de España y Marruecos del Museo de Madrid (Dipt. Pupip.). Eos, 8: 2941.

Gil Collado, J., 1935. Culícidos de la Isla de Fernando Póo recogidos por la expedición J. Gil-F. Bonet. Eos, 11: 311329.

GINER MARÍ, J. 1944. Resultados científicos de un viaje entomológico al Sáhara español y zona oriental del Marruecos español. Familias Sphecidae y Mutillidae (sensu lato) (Hym. Sphec. y Mut.). Eos, 20: 351-385.

Gogorza, J., 1878. Nota sobre crisídidos de Madrid. Actas Soc. Esp. Hist. Nat., 7: 52.

Gogorza, J., 1891. Reseña y guía de las colecciones del Museo de Historia Natural. Escuela Tipográfica del Hospicio. Madrid. $103 \mathrm{p}$

Graells, M. DE LA P,. 1850. Descripción de algunos insectos nuevos pertenecientes a la fauna central de España. Mem. R. Acad. Cienc. Madrid, 1(2): 109-163, 2 láms.

Graells, M. DE LA P,. 1858. Insectos nuevos de España, descubiertos y descritos por el Dr. D. M. de la Paz Graells. Mem. Comisión Mapa Geológico España (año de 1855): 36-112, 7 láms.

Horstmann, K. \& Bordera, S., 1995. Type revisions of Ichneumonidae (Hymenoptera) described by Kriechbaumer from Mallorca. NachrBl. Bayer. Entomol., 44(3/4):4956

IzQuiERdo Moya, I., 1984. Especies paleárticas de Enicospilus Steph., 1832 (Hym. Ichneumonidae, Ophioninae) del Instituto Español de Entomología. Bol. Asoc. Esp. Entomol., 8: 95-100.

Koch, M., 1948. Las Zygaena españolas del Instituto Español de Entomología (Lep. Zygaena). Eos 24: 319-333

Konow, FR.W., 1907. Neue Chalastogastra aus den naturhist. Museen in Hamburg und Madrid. Zeitschr. Syst. Hym. Dip., 7:161-174.

Llorente del Moral, V., 1967. Resultados de la expedicion Peris-Álvarez a la isla de Annobón. (12) Mantodea, Tettigonoidea y Acridoidea I. (Orthoptera). Eos, 43: 591622.

Martínez SÁEz, F. de P., 1886. Coleópteros de España y Norte de Africa recogidos por el Sr. Bolívar. Actas Soc. Esp. Hist. Nat., 15: 48-55.

Morales Agacino, E., 1940. Dermápteros del Marruecos español e Ifni. Rev. Fr. Entomol., 7: 69-72.

Morales Agacino, E., 1948. Apuntes sobre los Dictyoptera marroquíes del Instituto Español de Entomología. Eos, 24: 335-368.

Morales Agacino, E., 1950. Apuntes sobre los Phasmidae y Tettigoniidae marroquíes del Instituto Español de Entomología. Eos, 26: 157-196

Morales Agacino, E., 1951. Apuntes sobre los Dermaptera marroquíes del Instituto Español de Entomología. Eos, 27: 257-263.

Morales Agacino, E., 1956. Apuntes sobre los Gryllidae marroquíes del Instituto Español de Entomología. Eos, 32: 145-184.

NAVÁs, L., 1911. Algunos Neurópteros del Museo de Madrid. Asoc. esp. Progr. Cienc., Congr. Valencia, (1910), 5(Cienc. Nat.): 91-97. 
NieVES AlDREY, J.L., 1985. La colección de cinípidos gallícolas del Instituto Español de Entomología (Hym., Cynipidae, Cynipinae). Graellsia, 41: 113-124.

NOYES, J.S. 1981. On the types of the species of Encyrtidae described by R. Garcia Mercet (Hymenoptera, Chalcidoidea). Eos, 55-56: 165-189

PARís, M. 1994. Catálogo de tipos de orthopteroides (Insecta) de Ignacio Bolívar, I: Blattaria, Mantodea, Phasmoptera, y Orthoptera (Stenopelmatoidea, Rhaphidophoroidea, Tettigonioidea, Grylloidea, Tetrigoidea). Eos, (1993), 69: 143-264

Peinado, M.V. \& Mateos, J., 1986. La colección de efipigerinos del Museo Nacional de Ciencias Naturales (Orthoptera: Tettigoniidae). I. Actas VIII Jornadas Asoc. esp. Entomol.: 342-352.

Peinado, M.V. \& Mateos, J., 1986. La colección de efipigerinos del Museo Nacional de Ciencias Naturales (Orthoptera: Tettigoniidae). II. Actas VIII Jornadas Asoc. esp. Entomol:: 353-362.

Peláez, D., 1935. Membrácidos de Fernando Póo, Guinea Española y Kamerún (Hem. Homopt.). Eos, 11: 7-69.

Peris, S.V. 1963. Resultados de la expedición Peris-Álvarez a la isla de Annobón (Guinea española) 7. Diptera Muscidae. Bol. R. Soc. Esp. Hist. Nat. (Secc. Biol.), 61: 101-121.

PIC, M. 1905. Hylophilides nouveaux de la Guinée espagnole. Mem. Soc. Esp. Hist. Nat., 1: 201-208 .

Poey, F. 1832. Centurie des Lepidoptères de l'Île de Cuba. Paris.

Prado SaInZ, S., 1890. Sobre las especies españolas del género Pimelia que existen en la colección del Museo de Madrid. Actas Soc. Esp. Hist. Nat., 19: 107-110.

Pujol, M. 1943. Catálogo de Lepidópteros que se encuentran en la zona norte de los alrededores de Madrid. Graellsia, 1(2): 12-28, lám. 3; 1(3): 13-28; 1(4): 17-30; 1(5): 9-29.

Rey del Castillo, C. \& Izquierdo Moya, I., 1989. Tipos de especies de Himenópteros descritas por G. Ceballos, en el Museo Nacional de Ciencias Naturales de Madrid. Eos, 65(2): 251-264.

Rey del Castillo, C., 1989. Especies paleárticas de Banchini y Glyptini (Hym., Ichneumonidae) representadas en el Museo Nacional de Ciencias Naturales de Madrid. Bol. Asoc. esp. Entomol., 13: 183-193.
SAntoro, F.H. \& García de Viedma, M., 1965. Los Líctidos del Instituto Español de Entomología (Coleoptera). Graellsia, 21: 85-87.

SAnTos, C. 1994. Cátalogo de los insectos recolectados por la Comisión Científica del Pacífico (1862-1865). Serie de Manuales Técn. de Museología, no 5. B.Sanchíz (ed.). Museo Nacional de Ciencias Naturales. CSIC. 196 pág.

SElGA, D., 1960. Resultados de la expedición Peris-Álvarez a Annobón. II. Dos especies nuevas de Isotómidos (Collembola) de la isla de Annobón. Publ. Inst. Biol. Apl. Barcelona, 31: 93-100.

Selga, D., 1962. Resultados de la expedición Peris-Alvarez a la isla de Annobón (Golfo de Guinea) V. Colémbolos. Publ. Inst. Biol. Apl. Barcelona, 33: 17-31.

Sendra, A., 1989. Datos sobre Campodeidos del Museo Nacional de Ciencias Naturales de Madrid (Insecta, Diplura, Campodeidae). Eos, 65(1): 115-123.

Solano, J.M., 1871. Guía del Gabinete de Historia Natural. Imprenta Gregorio Juste. Madrid. 99 pp.

SuÁREZ, F.J. 1959. Mutílidos españoles nuevos o interesantes de la colección del Instituto Español de Entomología (Hymenoptera). Eos, 35: 97-112.

VIEJO, J.L., 1984. Contribución al conocimiento sobre las mariposas del Golfo de Guinea (Lep., Papilionoidea). Eos, 60: 335-369.

ZARCO, E. 1941. Los Cathoplius Thoms. del Instituto Español de Entomología (Col. Carab.). Eos, 17: 131-134, lám. 6.

ZuninO, M., 1977. Revisión de las especies paleárticas del subgénero Onthophagus (s. str.) Latr. Los tipos de J.M. de la Fuente y M. Pic en el Instituto Español de Entomología. Eos, 53: 315-319. 